\title{
Assisting and Opposing Stagnation Point Pseudoplastic Nano Liquid Flow towards a Flexible Riga Sheet: A Computational Approach
}

\author{
Aysha Rehman (D), ${ }^{1}$ Azad Hussain, ${ }^{1}$ and Sohail Nadeem² \\ ${ }^{1}$ Department of Mathematics, University of Gujrat, Gujrat 50700, Pakistan \\ ${ }^{2}$ Department of Mathematics, Quaid-I-Azam University, Islamabad 44000, Pakistan \\ Correspondence should be addressed to Aysha Rehman; aysharehman1986@gmail.com \\ Received 25 December 2020; Revised 8 April 2021; Accepted 3 May 2021; Published 17 May 2021 \\ Academic Editor: Jakub Grabski
}

Copyright ( $\odot 2021$ Aysha Rehman et al. This is an open access article distributed under the Creative Commons Attribution License, which permits unrestricted use, distribution, and reproduction in any medium, provided the original work is properly cited.

Nanofluids are used as coolants in heat transport devices like heat exchangers, radiators, and electronic cooling systems (like a flat plate) because of their improved thermal properties. The preeminent perspective of this study is to highlight the influence of combined convection on heat transfer and pseudoplastic non-Newtonian nanofluid flow towards an extendable Riga surface. Buongiorno model is incorporated in the present study to tackle a diverse range of Reynolds numbers and to analyze the behavior of the pseudoplastic nanofluid flow. Nanofluid features are scrutinized through Brownian motion and thermophoresis diffusion. By the use of the boundary layer principle, the compact form of flow equations is transformed into component forms. The modeled system is numerically simulated. The effects of various physical parameters on skin friction, mass transfer, and thermal energy are numerically computed. Fluctuations of velocity increased when modified Hartmann number and mixed convection parameter are boosted, where it collapses for Weissenberg number and width parameter. It can be revealed that the temperature curve gets down if modified Hartmann number, mixed convection, and buoyancy ratio parameters upgrade. Concentration patterns diminish when there is an incline in width parameter and Lewis number; on the other hand, it went upward for Brownian motion parameter, modified Hartmann, and Prandtl number.

\section{Introduction}

Mixed convection flow or a combination of free and forced convections exists in numerous electrify operations; both certainly occur in many engineering applications. Such applications mostly appear in heat exchangers, nuclear reactors, nanotechnology, atmospheric boundary layer flow, electronic equipment, and so on. These operations arise at some stage in the outcomes of buoyancy forces in combined convections or the effects of forced flow in free convection become significant [1]. The unsteady mixed convection flow closer to a stretching sheet throughout the years is an important kind of flow of functional substantial in engineering and industries [2]. Patel and Singh [3] investigated mixed convection micropolar fluid flow in a permeable medium with a magnetic field towards a nonlinearly extendable surface. Arifin et al. [4] discussed the dusty Williamson mixed convection fluid flow towards a stretchable surface with the impact of an aligned magnetic field. Ishak et al. [5] investigated the stagnation-point mixed convection viscous fluid flow towards a stretchable surface in its plane. The nonNewtonian fluid form is essential to conceive the fluid flow in the latest industrial materials, so that the work productiveness could be improved. Shafiq et al. [6] studied the bioconvective second-grade nano liquid flow in the presence of chemical reaction and buoyancy effect. Naganthran et al. [7] demonstrated a computational approach that inspects the behavior of mixed convection steady stagnation-point Powell-Eyring fluid flow on a vertical stretching/shrinking surface. Azeman and Ishak [8] discussed numerically the 
problem of the combined convection stagnation-point flow on a vertical sheet. Many researchers had also studied the mixed convectional flow [9-13].

The research of heat transmission triggered employing boundary layer flow of an incompressible fluid towards a stretched surface had received extended interest from the scientists and researchers due to its advantages in industry and engineering. Presently, huge exertion has been made to concentrate on this subject to the frame of reference of its different industrial and engineering applications. The effects of combined convection MHD on the boundary layer flow in the aspect of heat transport of Hematite-water nanofluid on a stretchable surface are demonstrated in [14]. Ahmad et al. [15] demonstrated the boundary layer flow by a curved stretched surface enclosed in a porous material.

Nowadays, to improve the abilities of heat transport of habitual fluids like water, glycerin, and engine oil because of the decay of the thermal effects, nanofluid is the classic bestowal to enhance the thermal conductivity. Nano liquid is a liquid that was invented by nanometer-sized particles and microfibers having a diameter less than $100 \mathrm{~nm}$. Nanofluids are used in many operations to fulfill industrial requirements, like propellant combustion, drug delivery, cooling of automotive engines, extraction of geothermal forces, and heat transfer. Al-Hossainy and Eid [16] demonstrated the heat transfer enhancement and DFT Structure and calculations in hybrid nanofluid flow as an application of potential solar cell coolant in a double tube. Zaib et al. [17] discussed the partial slip impacts on micropolar mixed convection fluid flow holding kerosene/water-based $\mathrm{TiO}_{2}$ nanoparticle over a Riga sheet; results were obtained for aiding and opposing flows. Choi was the first who introduced the idea of nanofluid. He suggested that a new category of heat exchanger liquids could be engineered by suspending metallic nanoparticles in conventional heat exchanger liquids [18]. Ahmed et al. [19] discovered the impact of variable viscosity on the MHD unsteady flow of carbon nanotubes on a shrinking surface. Saleem et al. [20] explored the theoretical treatment for the unsteady Walter's $B$ nanofluid flow over a rotating cone in the magnetic regime. Many researchers had discussed the flow of nanofluids [21-39].

Lorentz force theoretically [40] and experimentally [41] is an efficient agent to reduce skin friction. Nadeem et al. [42] demonstrated that flow is induced through exponentially stretching surface within the time-dependent thermal conductivity. Mahdy and Hoshoudy [43] explored the electromagnetohydrodynamic (EMHD) unsteady non-Newtonian nanotangent hyperbolic fluid that is electrically conducting towards a Riga surface in the presence of slip conditions and variable thickness.

The current examination adds a novel era for scientists to find the characteristics of pseudoplastic nanofluid. Here, we inspect heat transfer analysis and mixed convection stagnation-point flow of a pseudoplastic non-Newtonian nanofluid over a convectively heated flexible Riga plate. Obtained equations are solved by bvp $4 c$ numerically. The consequences of the given problem are demonstrated by parameters such as modified Hartmann number, mixed convection parameter, Brownian motion parameter, buoyancy ratio parameter, thermophoresis parameter, width parameter, stretching parameter, Weissenberg, Biot, Prandtl, and Lewis numbers to the velocity, thermal energy, and mass transmission towards the vertical elastic Riga plate.

\section{Mathematical Modeling}

We inspected the incompressible, two-dimensional, steady pseudoplastic nanofluid flow and heat transfer improvement examination over the vertical extendable Riga surface as shown in Figure 1. $u_{w}(x)=a x$ is the sheet stretched velocity and $u_{\infty}(x)=b x$ is the ambient fluid velocity, while the origin is fixed. It is assumed that the plate is heated by convection from a hot fluid at the temperature $T_{f}$ and the plate is heated by convection fluid at a temperature $T_{\infty}$ which is by heat transport coefficient $h_{f}$. Considering the Cartesian coordinates system, fluid flow velocity will change through $x$-axis and $y$-axis in a manner where the $x$ - axis is taken vertically and the $y$-axis is taken horizontally as shown below.

The elemental equation of pseudoplastic fluid is [44]

$$
\tau=\left[\mu_{\infty}+\left(\mu_{0}-\mu_{\infty}\right)\left((1+\Gamma \dot{\gamma})^{d}\right)^{(n-1 / d)}\right] A_{1},
$$

where zero shear rate viscosity is $\mu_{0}$, infinite shear rate viscosity is $\mu_{\infty}, \Gamma$ and $d$ are Carreau-Yasuda fluid parameters, $A_{1}$ is the Rivlin-Ericksen tensor, $\tau$ is the extra stress tensor, and $\dot{\gamma}$ is expressed as $\dot{\gamma}=\sqrt{\operatorname{tr}\left(A_{1}^{2}\right)(1 / 2)}$; here, $A_{1}=\left[(\operatorname{gradv})^{t}+\operatorname{gradv}\right]$. Take into account the fact that infinite shear rate viscosity $\mu_{\infty}=0$; then, equation (1) takes the form

$$
\tau=\left[\mu_{0}\left((1+\Gamma \dot{\gamma})^{d}\right)^{(n-1 / d)}\right] A_{1}
$$

and, under these considerations, governing equations can be written as follows: 


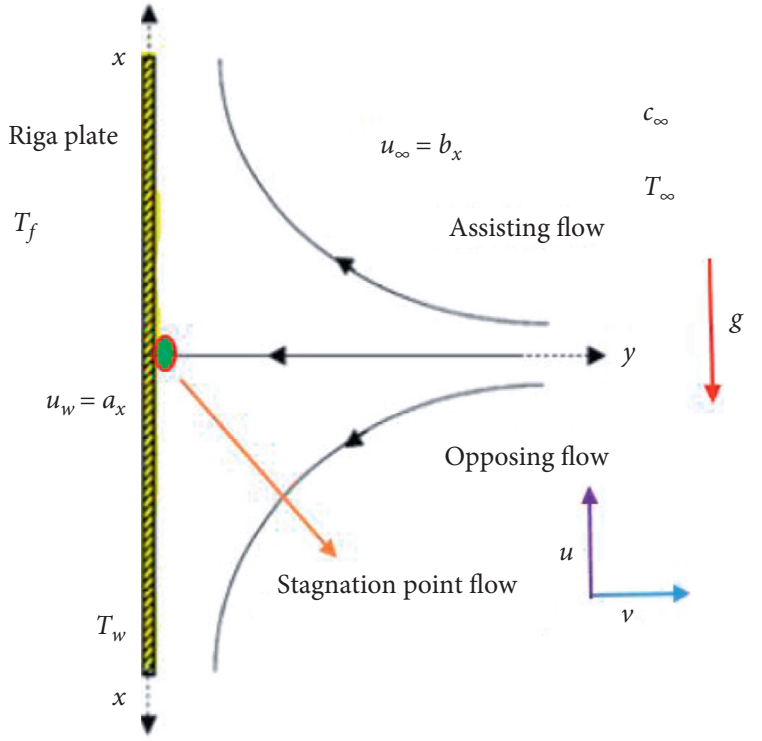

(a)

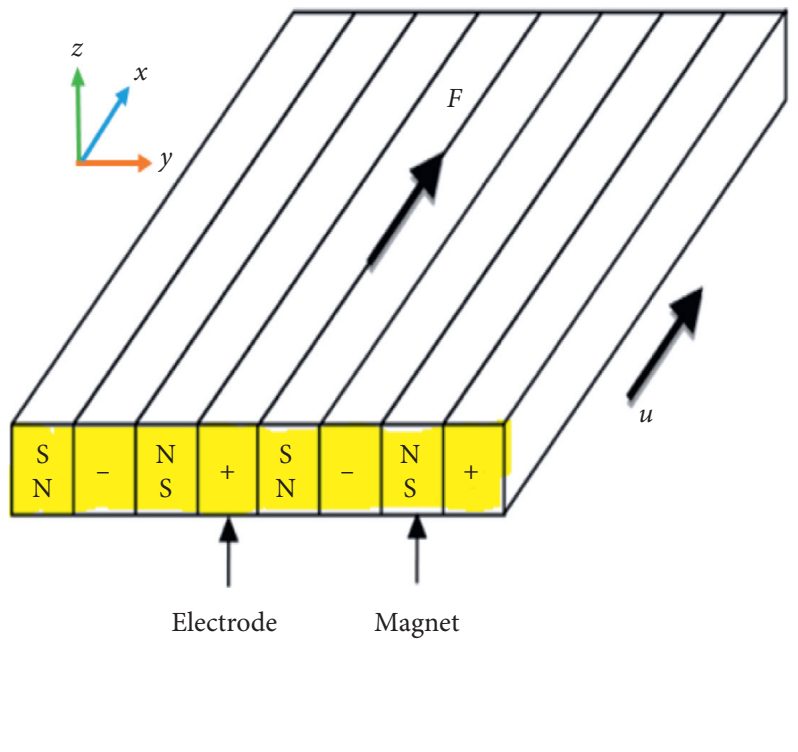

(b)

Figure 1: Sketch of the flow problem. (a) Physical geometry of the problem. (b) Riga plate.

$$
\begin{aligned}
\frac{\partial u}{\partial x}+\frac{\partial v}{\partial y}= & 0 \\
u \frac{\partial u}{\partial x}+v \frac{\partial u}{\partial y}= & u_{\infty} \frac{\mathrm{d} u_{\infty}}{\mathrm{d} x}+\nu \frac{\partial^{2} u}{\partial y^{2}}+v\left[\frac{(n-1)}{d} \cdot(d+1) \Gamma^{d}\left(\frac{\partial u}{\partial y}\right)^{d} \frac{\partial^{2} u}{\partial y^{2}}\right] \\
& +g\left[\frac{(1-C) \beta \rho_{f m}}{\rho_{f}}\left(T-T_{\infty}\right)-\left(\frac{\rho_{p}-\rho_{f m}}{\rho_{p}}\right)\left(C-C_{\infty}\right)\right]+\frac{\pi j_{0} M_{0}}{8 \rho_{f}} e^{-\left(\pi / a_{1}\right) y}, \\
u \frac{\partial T}{\partial x}+v \frac{\partial T}{\partial y}= & \alpha \frac{\partial^{2} T}{\partial y^{2}}+\frac{\left(\rho c_{p}\right)_{p}}{\left(\rho c_{p}\right)_{f}}\left[D_{B} \frac{\partial C}{\partial y} \frac{\partial T}{\partial y}+\left(\frac{D_{T}}{T_{\infty}}\right)\left(\frac{\partial T}{\partial y}\right)^{2}\right], \\
u \frac{\partial C}{\partial x}+v \frac{\partial C}{\partial y}= & D_{B} \frac{\partial^{2} C}{\partial y^{2}}+\left(\frac{D_{T}}{T_{\infty}}\right) \frac{\partial^{2} T}{\partial y^{2}} .
\end{aligned}
$$

In the above equations, $u$ and $v$ are the velocity components in the $x$-axis and $y$-axis, respectively, $v$ is the viscosity coefficient, $\left(\left(\rho c_{p}\right)_{p} /\left(\rho c_{p}\right)_{f}\right)$ is the proportion of nanoparticles heat capacity to that of the based fluid heat capacity, $\alpha$ is the thermal diffusivity of the based fluid, $\rho_{f}$ is the density of the base fluid, $c_{p}$ is the constant pressure specific heat, $D_{T}$ is thermophoresis diffusion coefficient, $D_{B}$ is Brownian diffusion coefficient, and the subscripts $\infty, f$, and $n p$ denote the values very far away from the solid surface, base fluid, and the nanoparticles, respectively.

The subjected boundary conditions are 


$$
\begin{aligned}
u & =u_{w}(x)=a x, \\
v & =0, \\
-k \frac{\partial T}{\partial y} & =h_{f}\left(T_{f}-T\right), \\
D_{B} \frac{\partial c}{\partial y}+\left(\frac{D_{T}}{T_{\infty}}\right) \frac{\partial T}{\partial y} & =0 \text { at } y \longrightarrow 0, \\
u & =u_{\infty}(x)=b x, \\
T \longrightarrow T_{\infty}, & \\
C \longrightarrow C_{\infty}, \text { at } y \longrightarrow \infty . &
\end{aligned}
$$

Invoking similarity variables are defined as,

$$
\begin{aligned}
\psi & =\sqrt{a v} x f(\eta), \\
\eta & =\sqrt{\frac{a}{v}} y, \\
u & =\frac{\partial \psi}{\partial y}=a x f^{\prime}(\eta), \\
v & =-\frac{\partial \psi}{\partial x}, \\
\theta(\eta) & =\frac{T-T_{\infty}}{T_{f}-T_{\infty}}, \\
\varphi(\eta) & =\frac{C-C_{\infty}}{C_{\infty}} .
\end{aligned}
$$

By using the upper relationships, the continuity equation (3) is satisfied automatically. Equation (3) becomes the form of ordinary differential equations:

$$
\begin{aligned}
& {\left[1+\frac{(n-1))}{d}(d+1) W_{e}^{d}\left(f^{\prime \prime}\right)^{d}\right] f^{\prime \prime \prime}+r^{2}} \\
& +f f^{\prime \prime}-\left(f^{\prime}\right)^{2}+\lambda \theta-N_{r} \varphi+Z e^{-\gamma \eta}=0, \\
& \frac{1}{\operatorname{Pr}} \theta^{\prime \prime}+\theta^{\prime} f+N b \varphi^{\prime} \theta^{\prime}+N t\left(\theta^{\prime}\right)^{2}=0, \\
& \varphi^{\prime \prime}+\operatorname{LePr} f \varphi^{\prime}+\frac{N t}{N b} \theta^{\prime \prime}=0,
\end{aligned}
$$

with boundary conditions

$$
\begin{aligned}
f & =0, \\
f^{\prime} & =1, \\
\theta^{\prime} & =-B i(1-\theta), \\
N b \varphi^{\prime}+N t \theta^{\prime} & =0 \text { at } \eta \longrightarrow 0, \\
f^{\prime} & =r, \\
\theta & =0, \\
\varphi & =0 \text { at } \eta \longrightarrow \infty .
\end{aligned}
$$

Here, prime denotes derivative for $\eta$, and other dimensionless characteristics are demonstrated as

$$
\lambda=\frac{(1-c) \beta \rho_{f m}\left(T_{f}-T_{\infty}\right) g}{a^{2} x \rho_{f}},
$$

$$
\begin{aligned}
N_{r} & =\frac{\left(\rho_{p}-\rho_{f m}\right) c_{\mathrm{o}} g}{a^{2} x \rho_{f}}, \\
r & =\frac{b}{a},
\end{aligned}
$$

$W_{e}^{d}=\left(\frac{a^{3 / 2} x \Gamma}{\sqrt{v}}\right)^{d}$,

$N t=\frac{\left(\rho c_{p}\right)_{p} D_{T}\left(T_{f}-T_{\infty}\right)}{\left(\rho c_{p}\right)_{f} \nu T_{\infty}}$,

$\operatorname{Pr}=\frac{\nu}{\alpha}$

$N b=\frac{\left(\rho c_{p}\right)_{p} D_{B} C_{\infty}}{\left(\rho c_{p}\right)_{f} v}$,

$L e=\frac{\alpha}{D_{B}}$,

$B i=\frac{h_{f}}{k} \sqrt{\frac{v}{a}}$,

$\alpha=\frac{K}{\left(\rho c_{p}\right)_{f}}$,

$Z=\frac{\pi j_{0} M_{0} x}{8 \rho_{p} u_{w}^{2}}$,

$\gamma=\frac{-\pi}{a_{1} \sqrt{\left(a / v_{f}\right)}}$. 
Here, $L e, N_{r}, \lambda, B i$, and $W_{e}$ denote Lewis number, buoyancy ratio parameter, mixed convection parameter, Biot number, and Weissenberg number, respectively, the symbol $Z$ represents modified Hartmann number, $\gamma$ denotes width parameter, Pr denotes Prandtl number, $r$ is the stretching parameter, $\mathrm{Nb}$ is the Brownian motion characteristic, and $N t$ denotes the thermophoresis characteristics.

The skin friction coefficient $C_{f}$ and local Nusselt number $N u_{x}$ definitions are

$$
\begin{aligned}
C_{f} & =\frac{\tau_{w}}{\rho u_{w}^{2}} \\
N u_{x} & =\frac{x q_{w}}{k\left(T_{f}-T_{\infty}\right)},
\end{aligned}
$$

where $q_{w}$ represents surface heat flux, $\tau_{w}$ represents surface shear stress, and $q_{m}$ represents surface mass flux, where pseudoplastic fluid is

$$
\begin{aligned}
& \tau_{w}=\left[\mu\left(1+\left(\frac{n-1}{d}\right) \Gamma^{d}\left(\frac{\partial u}{\partial y}\right)^{d}\right) \frac{\partial u}{\partial y}\right]_{y=0}, \\
& q_{w}=-k\left[\frac{\partial T}{\partial y}\right]_{y=0},
\end{aligned}
$$

and, by using appropriate similarity variable equation (5), the expressions for skin friction and local Nusselt number become,

$$
\begin{aligned}
C_{f} \operatorname{Re}_{x}^{1 / 2} & =\left[f^{\prime \prime}(0)+\left(\frac{(n-1)}{d}\right) W_{e}^{d}\left(f^{\prime \prime}(0)\right)^{d+1}\right], \\
N u_{x} \operatorname{Re}_{x}^{-1 / 2} & =-\theta^{\prime}(0),
\end{aligned}
$$

\section{Results and Discussion}

The obtained flow of nonlinear differential equation (6) with boundary conditions (7) was numerically worked out by MATLAB program bvp4c method. In the present study, there is a strong focus on the importance of the behavior of physical characteristics associated with the fluid temperature, velocity, and concentration, and those are presented in the form of graphs and have been demonstrated splendidly. Figure 2 describes the behavior of the modified Hartmann number in the form of adding flow and opposing flow. Field of velocity inclined by increased values of $Z$ and declined whenever the value of $(Z<0)$. Figure 3 demonstrates the performance of $\lambda$ on $f^{\prime}(\eta)$. Here, $\lambda$ behaves increments when the values of $\lambda$ rise, and a contrary behavior was shown for reverse flow. In Figure 4, boundary layer thickness expands immediately, with the value of $N_{r}$ growing. It is also noticeable that the conflicting flow $N_{r}$ declined. Figure 5 defines the variations of $\mathrm{Nb}$ on the velocity field, and it is revealed that thickness goes down in assisting flow, while it moves upward in case of increased values of $\mathrm{Nb}$. Figure 6 shows the flow of $B i$ on the velocity pattern. With the increment of $B i$, distribution of $f^{\prime}(\eta)$ ascends. Figure 7

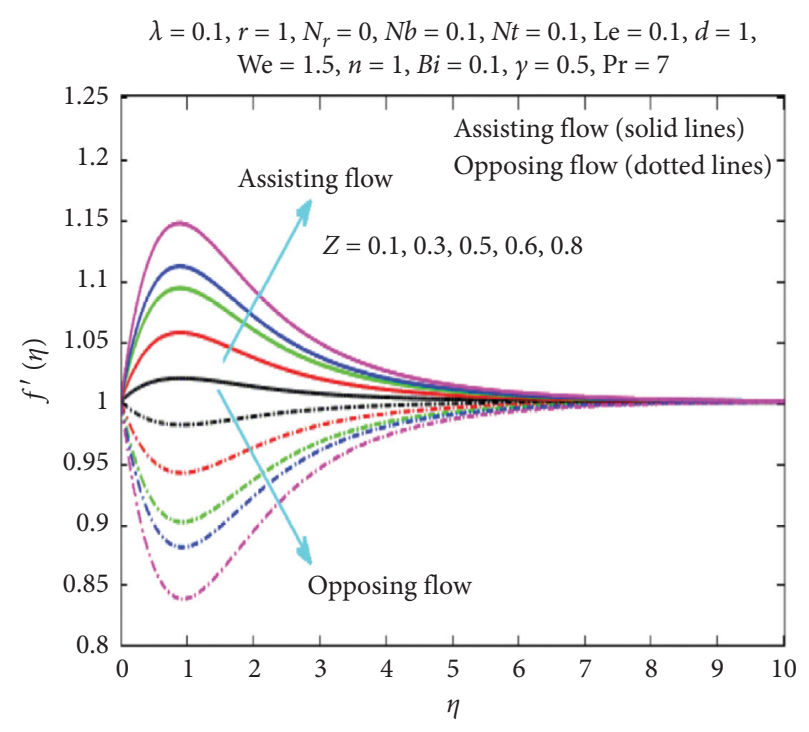

Figure 2: Consequences of $Z$ on $f^{\prime}(\eta)$.

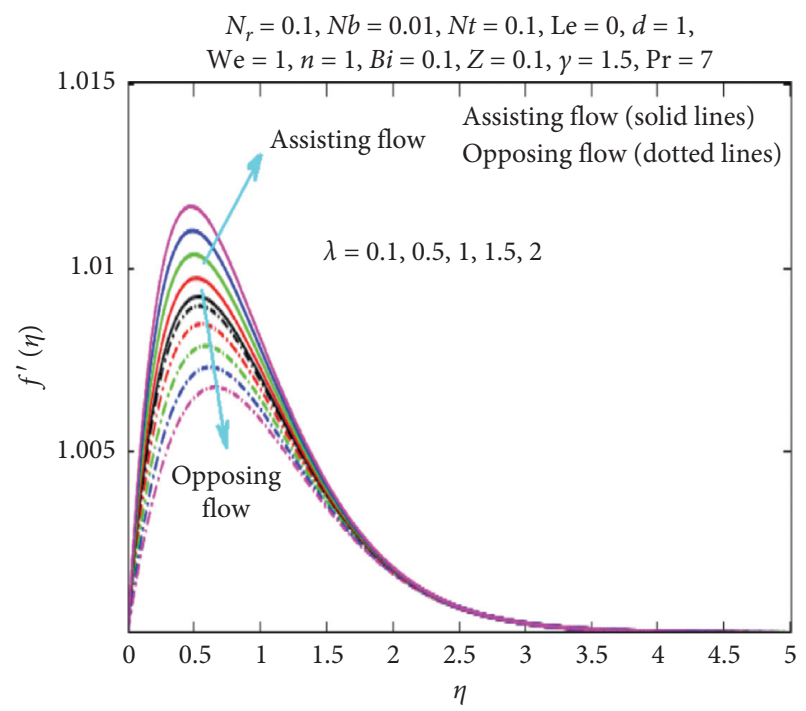

Figure 3: Result of $\lambda$ on $f^{\prime}(\eta)$.

discusses the affection of $\gamma$ on velocity flow; in this case, the value of $\gamma$ grows and the boundary layer thickness diminishes. Figure 8 shows the structure of $N t$ velocity model. It can be seen that field of velocity gets larger with the values of $N t$ addition. Figures 9-11 show the exhibited impression of $\operatorname{Pr}$ and $W_{e}$ on $f^{\prime}(\eta)$; the profile of $f^{\prime}(\eta)$ gets larger with the increment in the values of $\operatorname{Pr}$ and $W_{e}$. Figure 10 shows that while $r$ is increased, boundary layer width increases. Variation of temperature flow is demonstrated in Figures 12-19. Figure 12 discusses the influence of $\mathrm{Bi}$ on temperature field, whether the value of Biot number grow temperature sketched expand. It is noted that when the value of Le becomes larger, the profile of $\theta(\eta)$ goes down, in Figure 13. It is revealed that impact of $\gamma$ on $\theta(\eta)$ is that when we increase the value of $\gamma$ temperature curve enhance for aiding flow and for opposing flow curve moves down in Figure 14. Figure 15 examines the performance of $r$ on $\theta(\eta)$. 


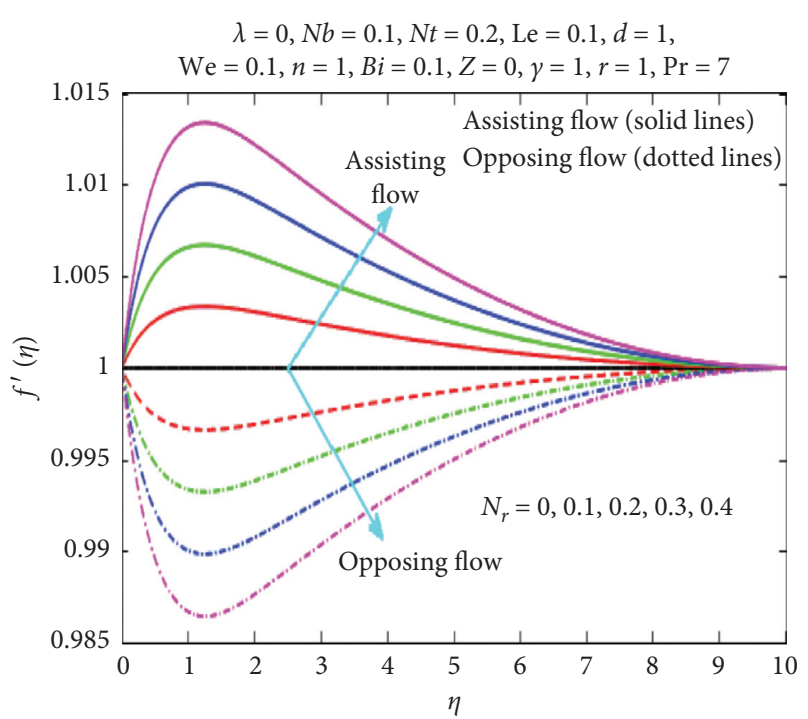

FIgURE 4: Influence of $N_{r}$ on $f^{\prime}(\eta)$.

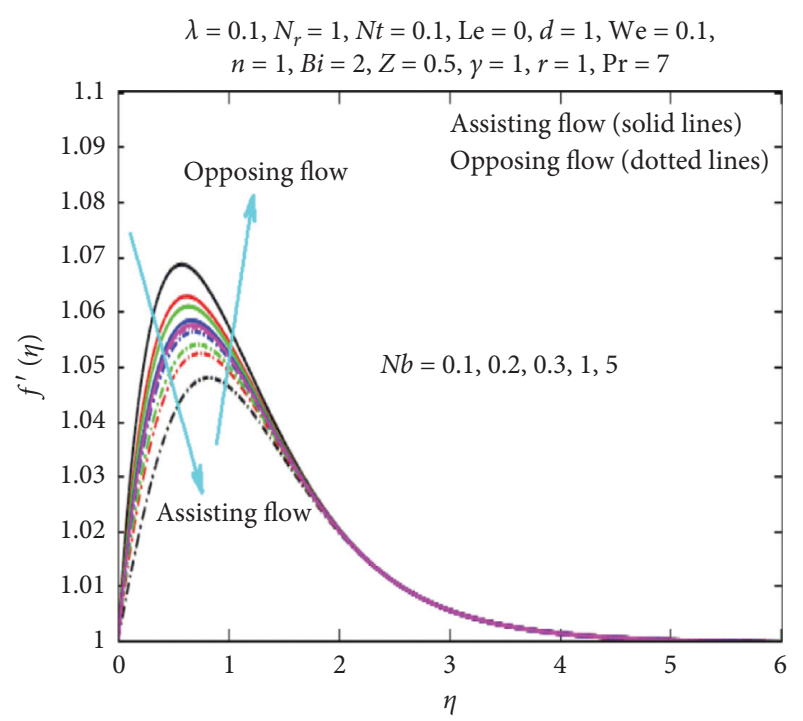

Figure 5: Impact of $N b$ on $f^{\prime}(\eta)$.

In opposing and assisting flow, $r$ shrinks on $\theta(\eta)$. Figure 16 obtaines the implication of $N b$. It shows that $\theta(\eta)$ becomes larger for increased values of $N b$. Figures 17 and 18 show the behaviors of $N t$ and $\mathrm{Pr}$, respectively; both are sketched towards down when the values of $N t$ and Pr grow. It can be easily observed that assisted flow falls and conflicting flow moves up for bigger values of $Z$ on $\theta(\eta)$ in Figure 19.

Deviation of concentration field can be revealed in Figures 20-27. Figure 20 describes the effect of $Z$ on $\varphi(\eta)$; the value of $Z$ grows and then the boundary layer increases for aiding flow and decreases in opponent flow. Figure 21 shows that when we increase the values of $\gamma$, the concentration curve falls in assisting flow and moves up in opposing flow. It is noticeable that Figures 22 and 23 indicate the

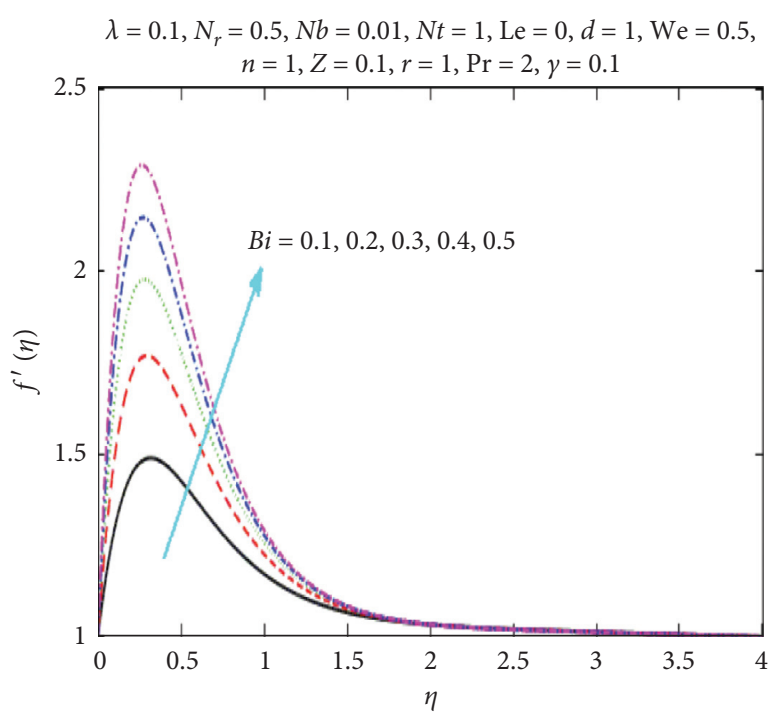

Figure 6: Variation of $B i$ on $f^{\prime}(\eta)$.

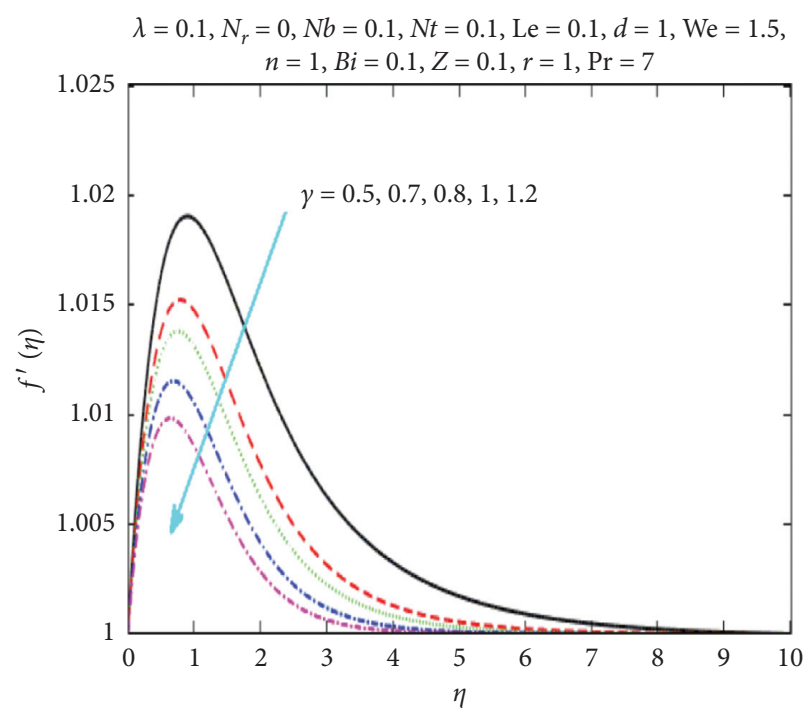

FIgURE 7: Upshot of $\gamma$ on $f^{\prime}(\eta)$.

performance of nanofluid parameters $\mathrm{Nt}$ and $\mathrm{Nb}$ on $\varphi(\eta)$, respectively. Both are dissimilar graphs; the pattern of $\varphi(\eta)$ diminishes in aiding flow and increases in opposing flow if the values of $N t$ bigger than the contrary graph are shown for $\mathrm{Nb}$. Figures 24 and 25 explore the efficiency of $\mathrm{Bi}$ and $\mathrm{Le}$ over $\varphi(\eta)$. The boundary layer width falls whenever the value of one and the other increases. Figures 26 and 27 depict the behavior of $r$ and Pr one by one. The impact of these two parameters on $\varphi(\eta)$ is that the growth of these parameters caused boundary layer increment. Figures 28-33 are created to examine the influence of $\lambda$ and $Z$ on streamlines. Table 1 is investigated; extensions in $N b, N t, L e, B i, \operatorname{Pr}$, and $Z$ caused heat transfer coefficient to upgrade and degrade by the increase of $\gamma$. The consequences of $\lambda$ on Nusselt numbers 


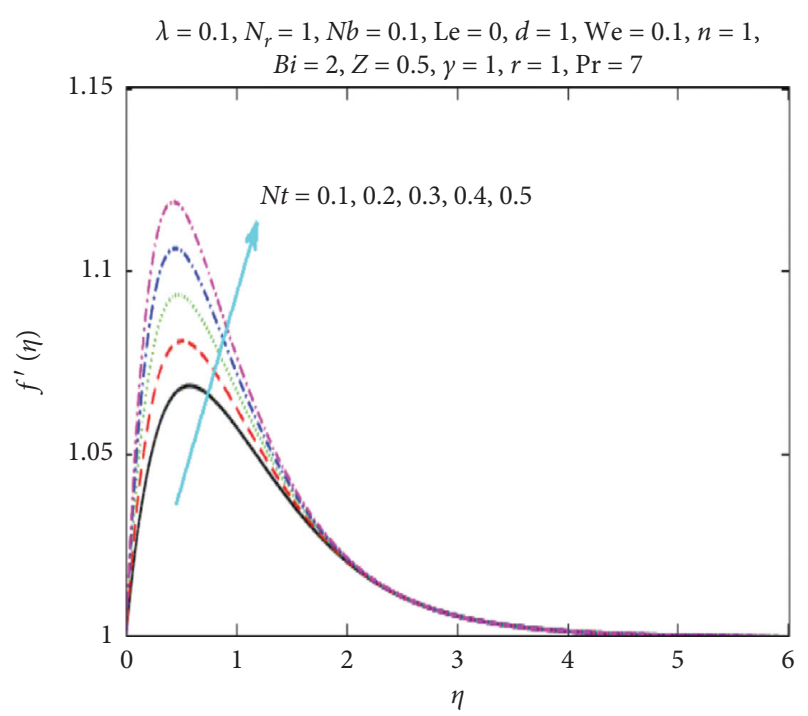

Figure 8: Effect of $N t$ on $f^{\prime}(\eta)$.

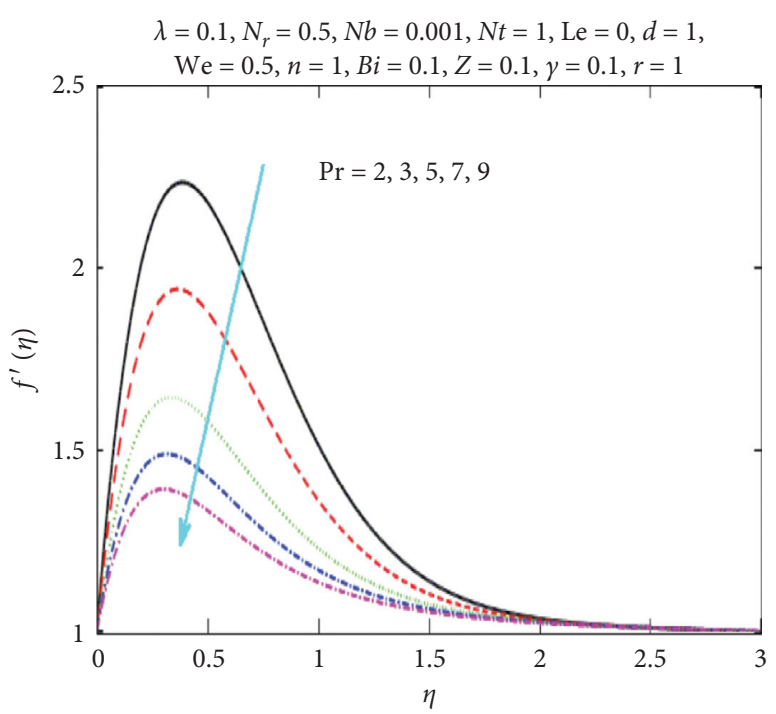

Figure 9: Result of $\operatorname{Pr}$ on $f^{\prime}(\eta)$.

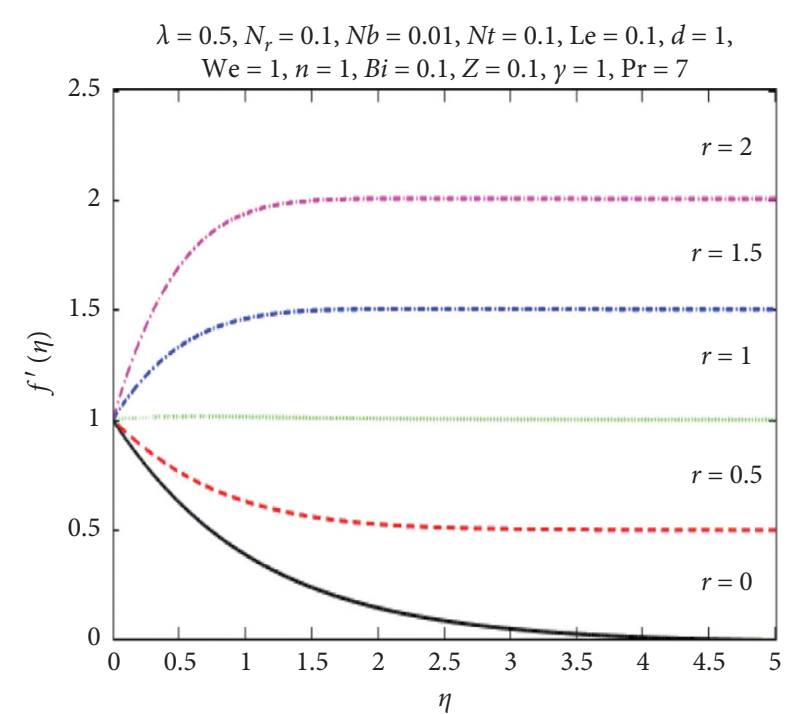

Figure 10: Influence of $r$ on $f^{\prime}(\eta)$.

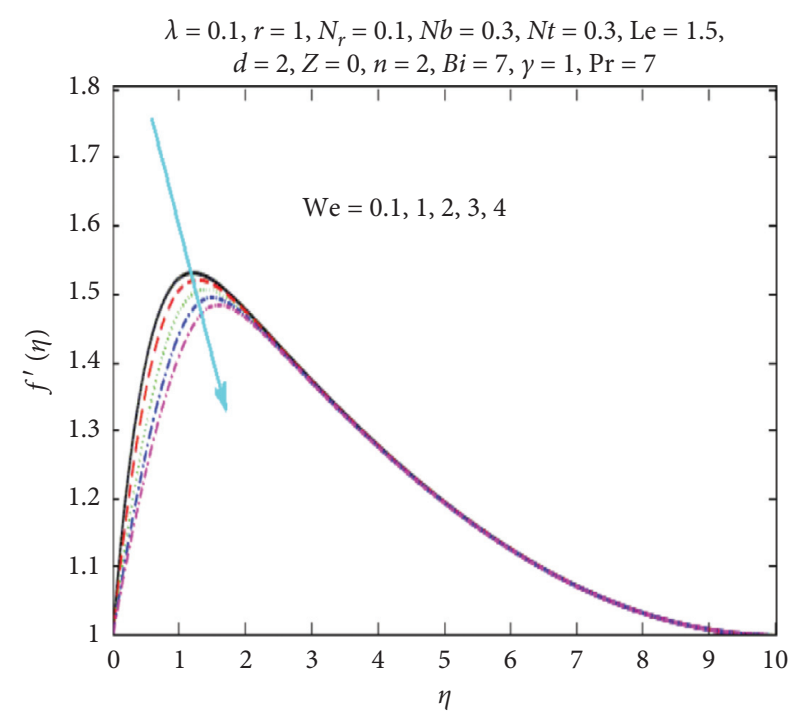

Figure 11: Consequences of $W_{e}$ on $f^{\prime}(\eta)$.

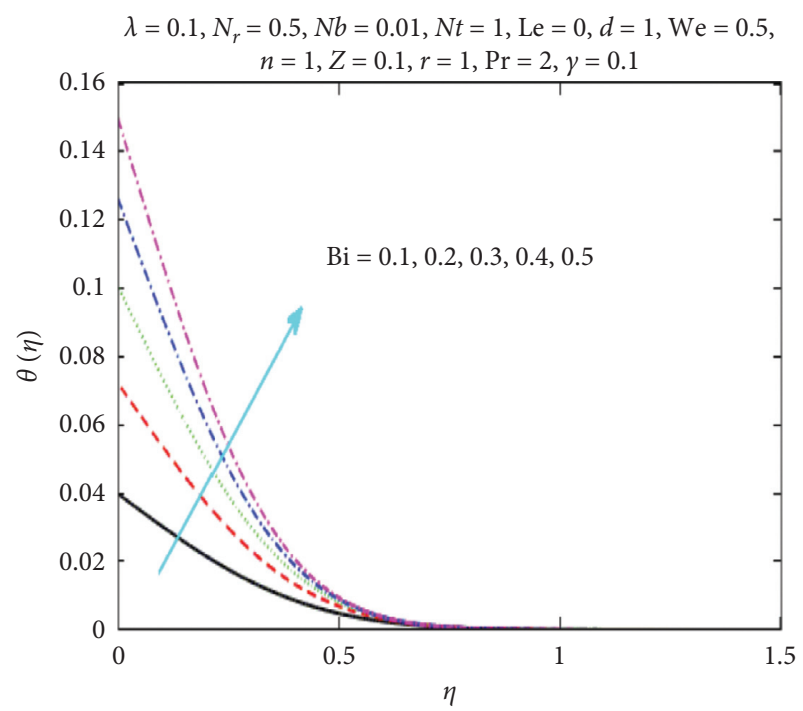

Figure 12: Impact of $B i$ on $\theta(\eta)$.

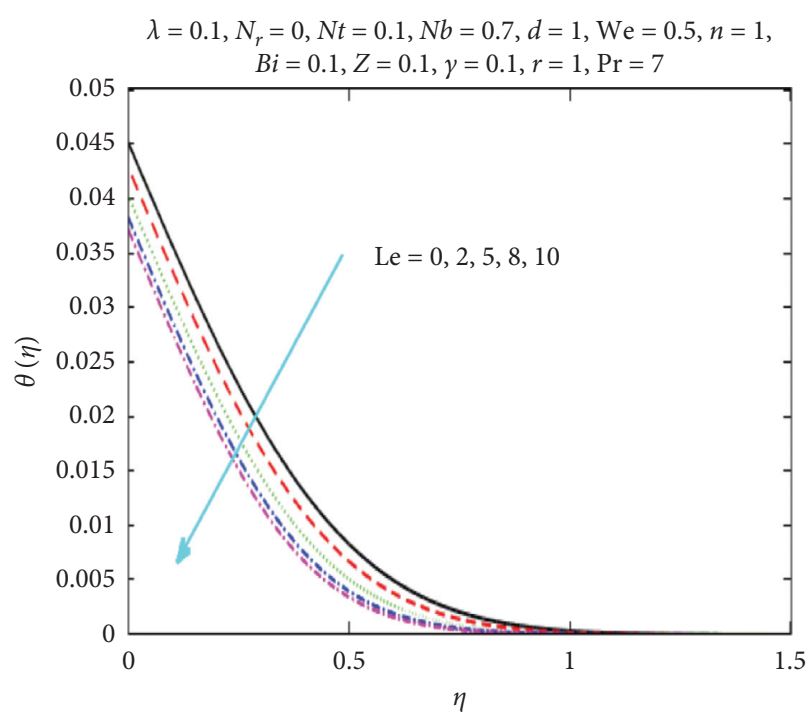

Figure 13: Upshot of Le on $\theta(\eta)$. 


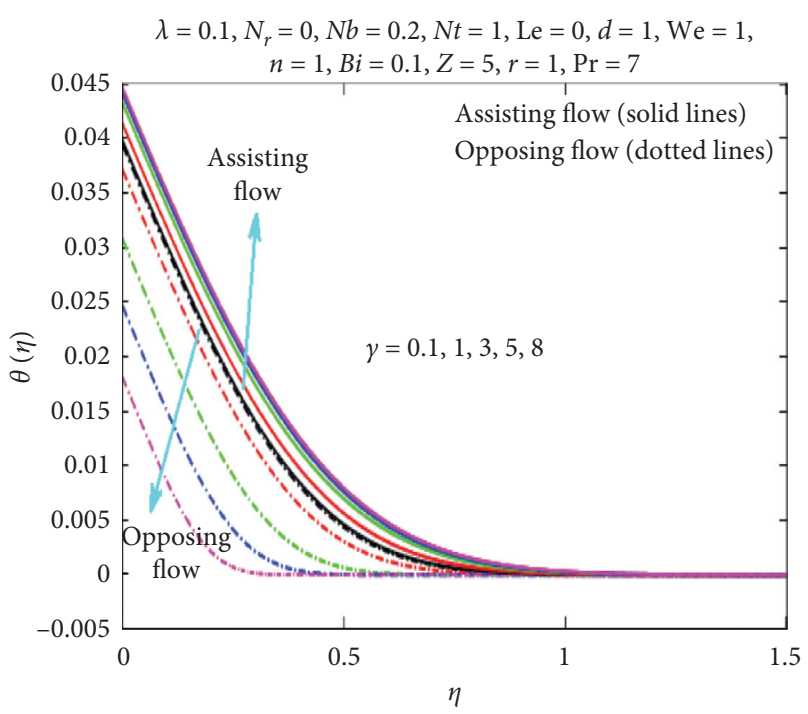

Figure 14: Effect of $\gamma$ on $\theta(\eta)$.

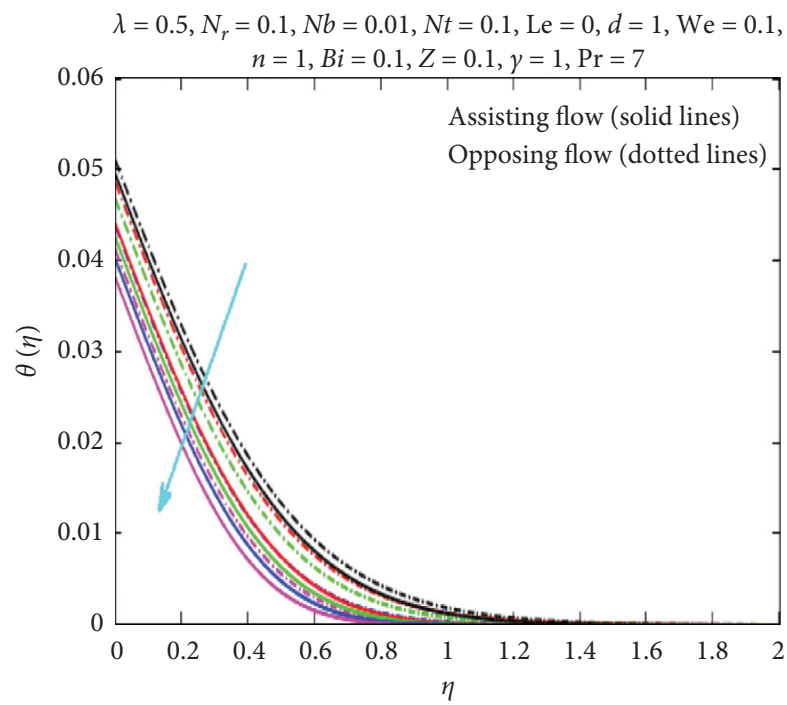

Figure 15: Impact of $r$ on $\theta(\eta)$.

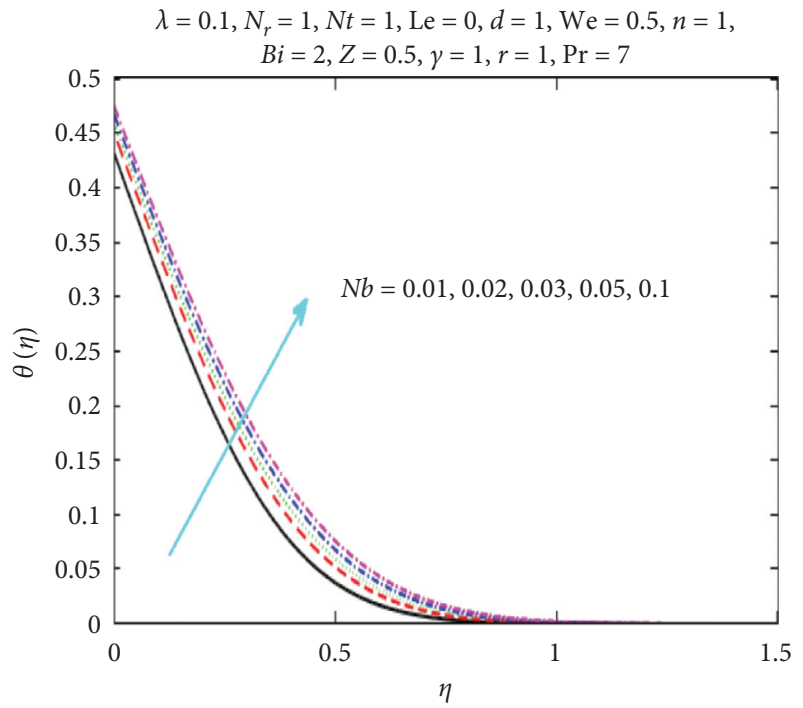

Figure 16: Deviation of $N b$ on $\theta(\eta)$.

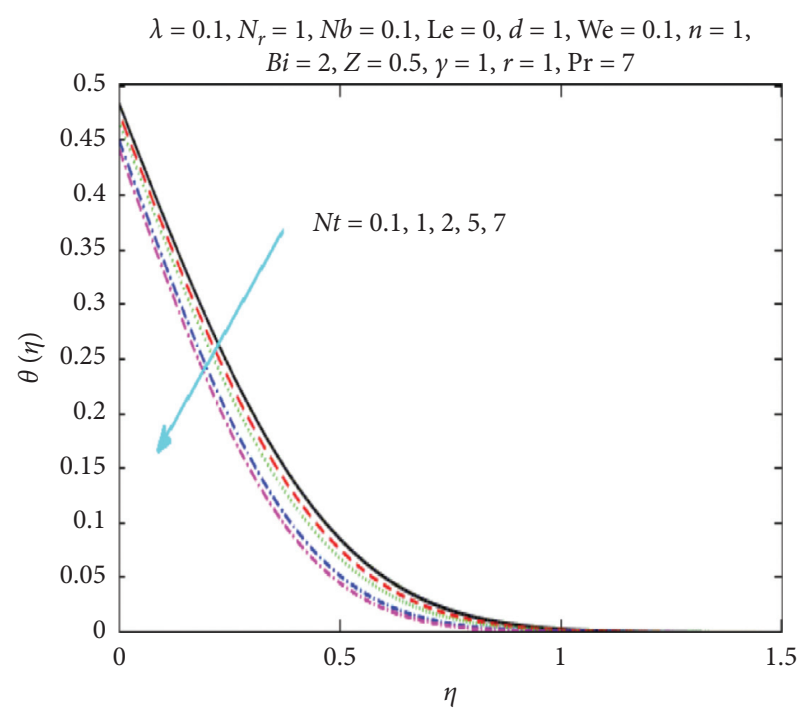

Figure 17: Influence of $N t$ on $\theta(\eta)$.

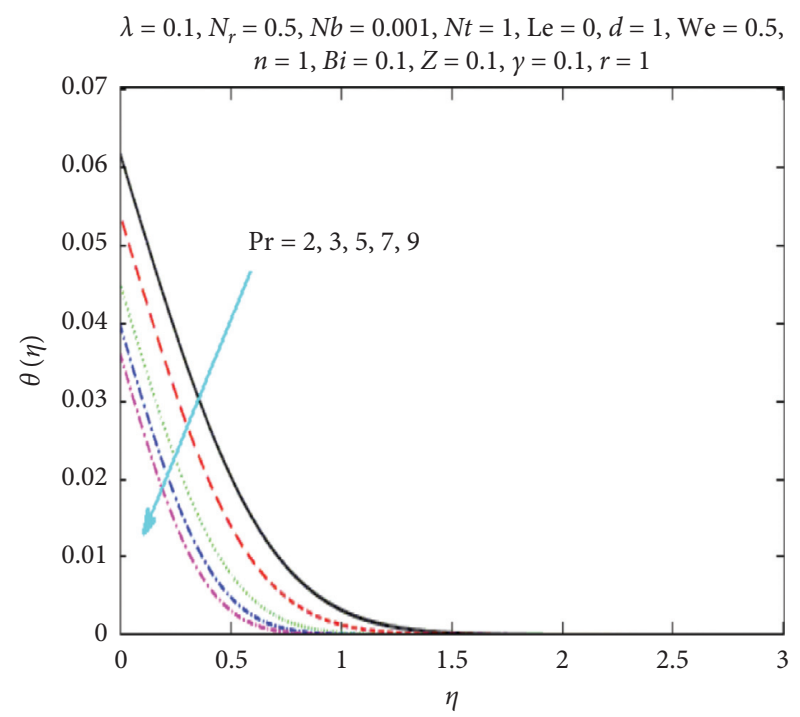

Figure 18: Impact of $\operatorname{Pr}$ on $\theta(\eta)$.

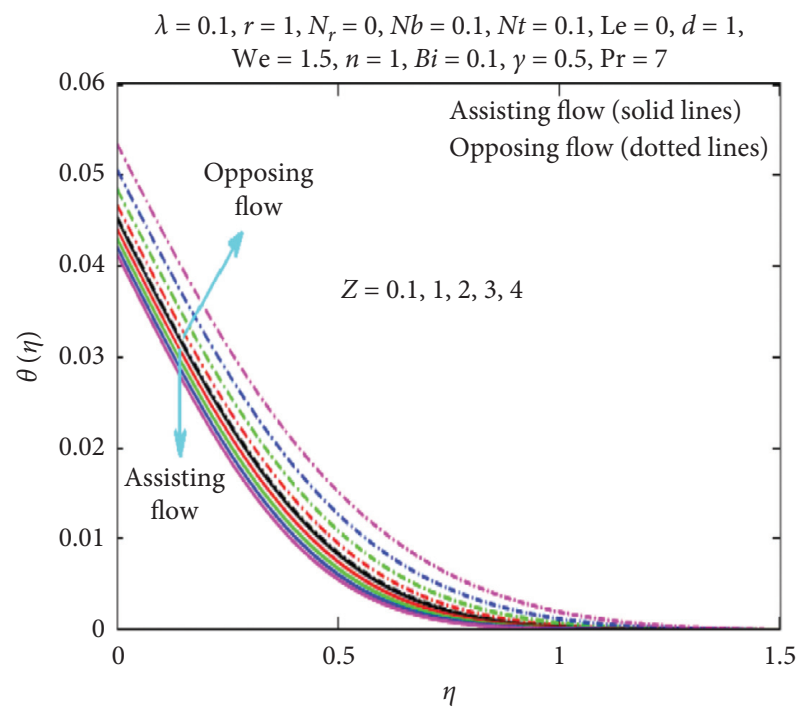

Figure 19: Consequences of $Z$ on $\theta(\eta)$. 


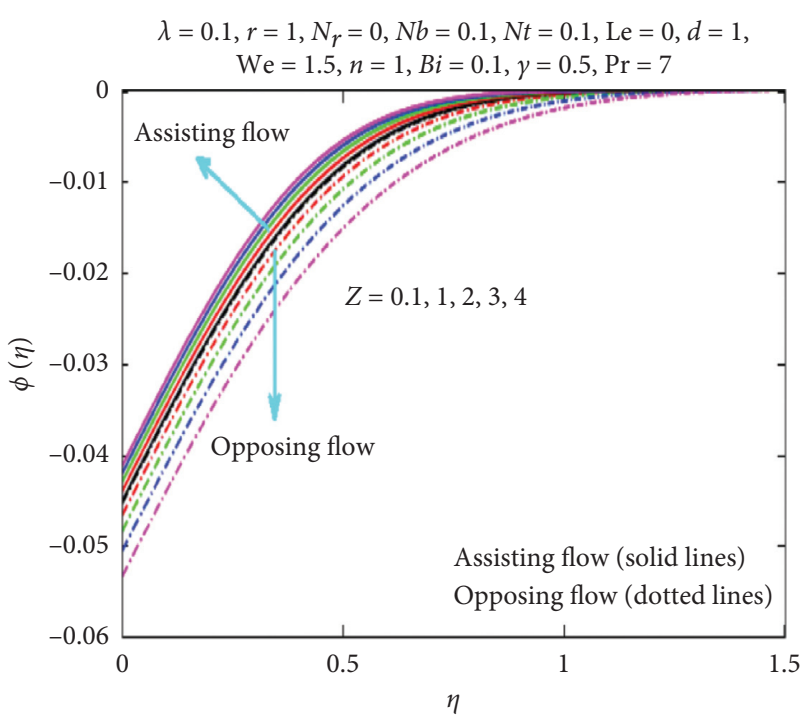

Figure 20: Impact of $Z$ on $\phi(\eta)$.

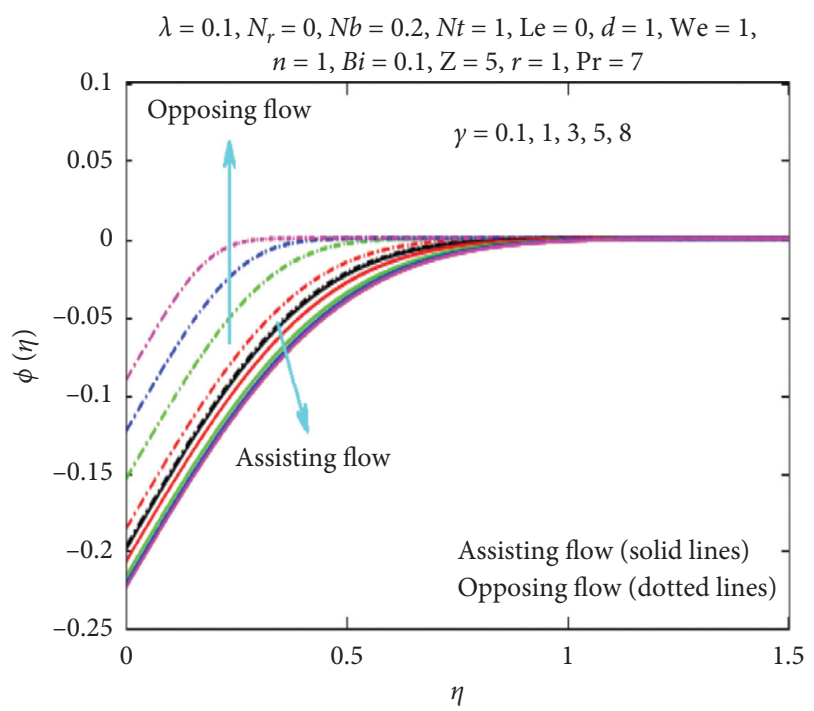

Figure 21: Effect of $\gamma$ on $\phi(\eta)$.

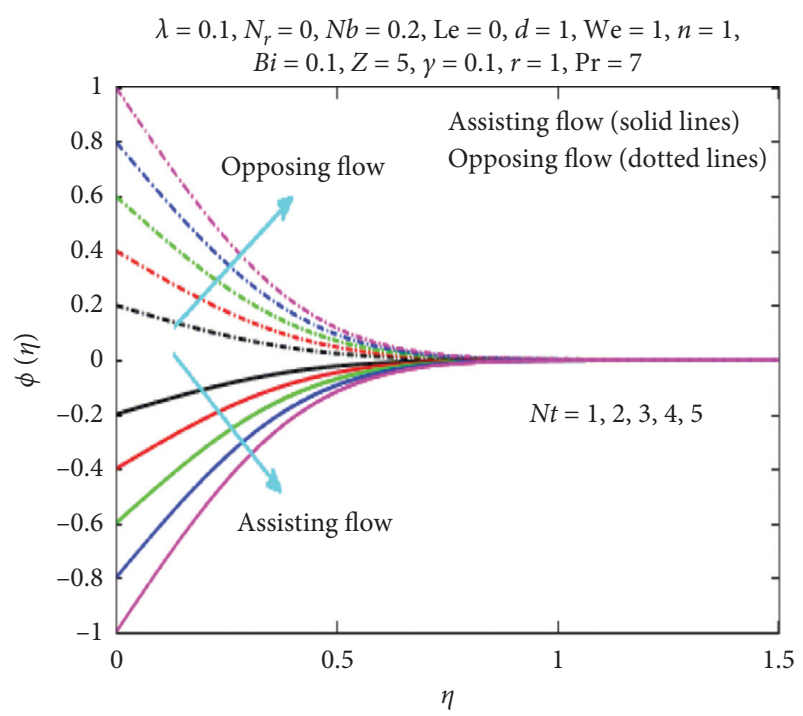

FIgURe 22: Influence of $N t$ on $\phi(\eta)$.

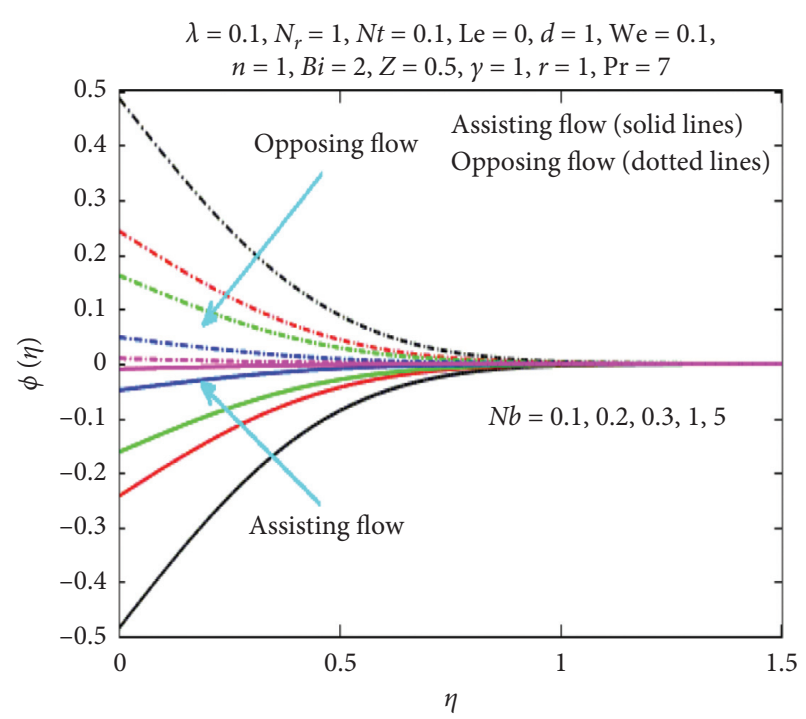

Figure 23: Consequence of $N b$ on $\phi(\eta)$.

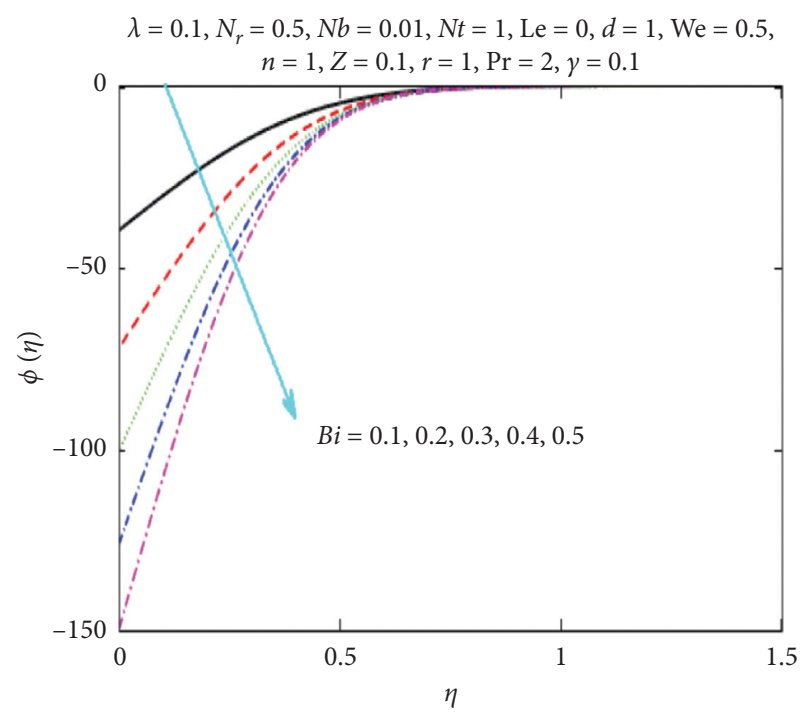

Figure 24: Influence of $B i$ on $\phi(\eta)$.

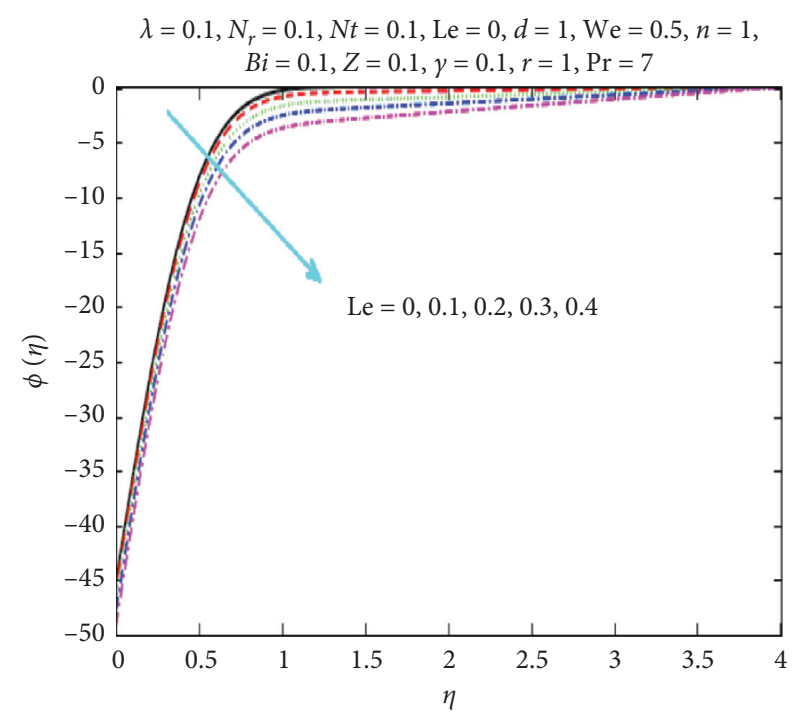

FIGURE 25: Result of Le on $\phi(\eta)$. 


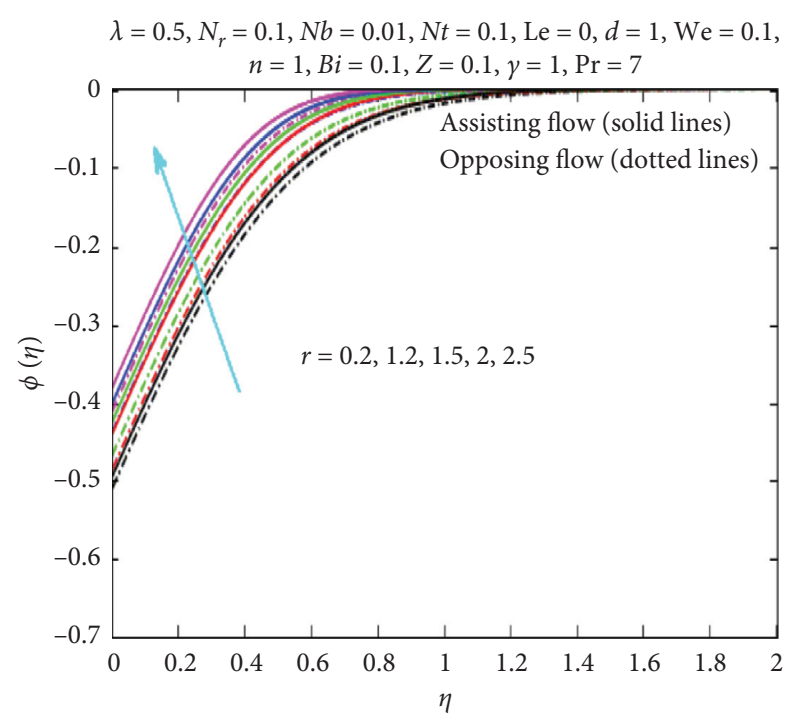

FIgURE 26: Upshot of $r$ on $\phi(\eta)$.

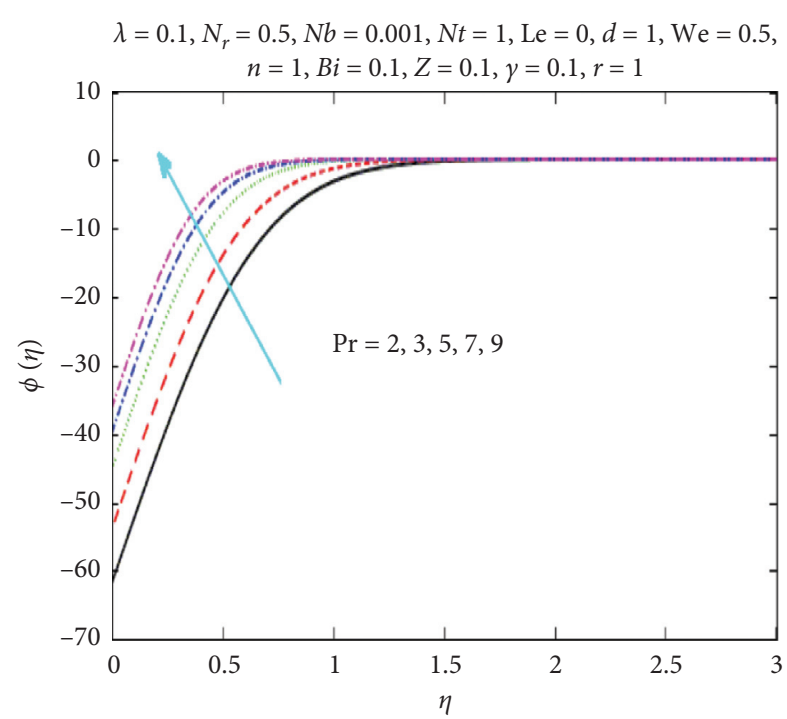

Figure 27: Consequences of $\operatorname{Pr}$ on $\phi(\eta)$.

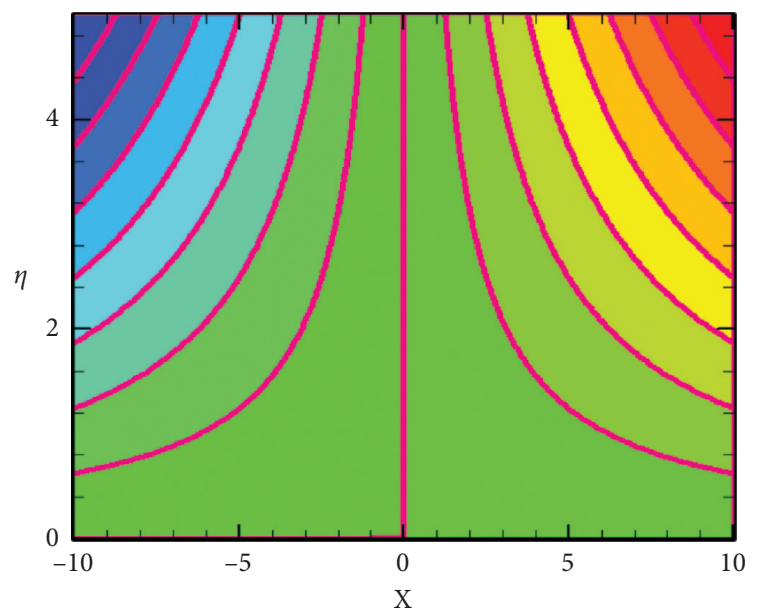

FIGURE 28: Streamlines for $\lambda=0.1$.

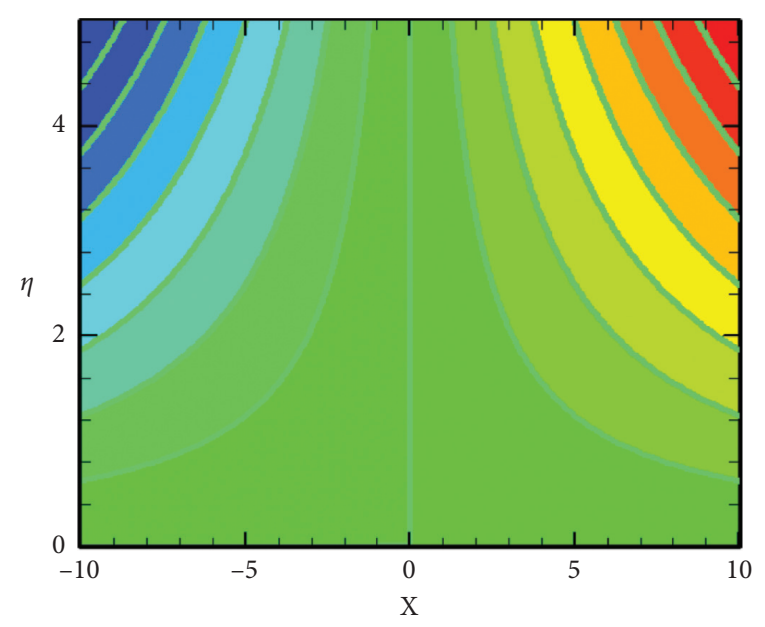

Figure 29: Streamlines for $\lambda=1$.

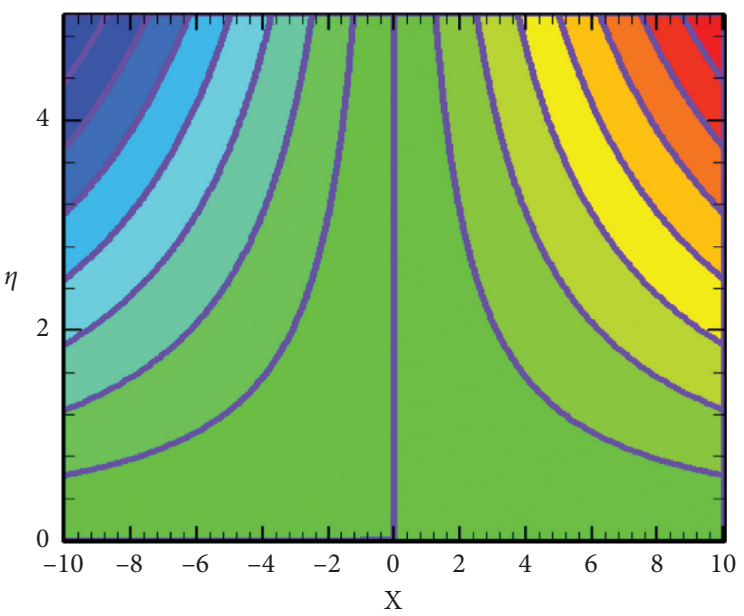

Figure 30: Streamlines for $\lambda=2$.

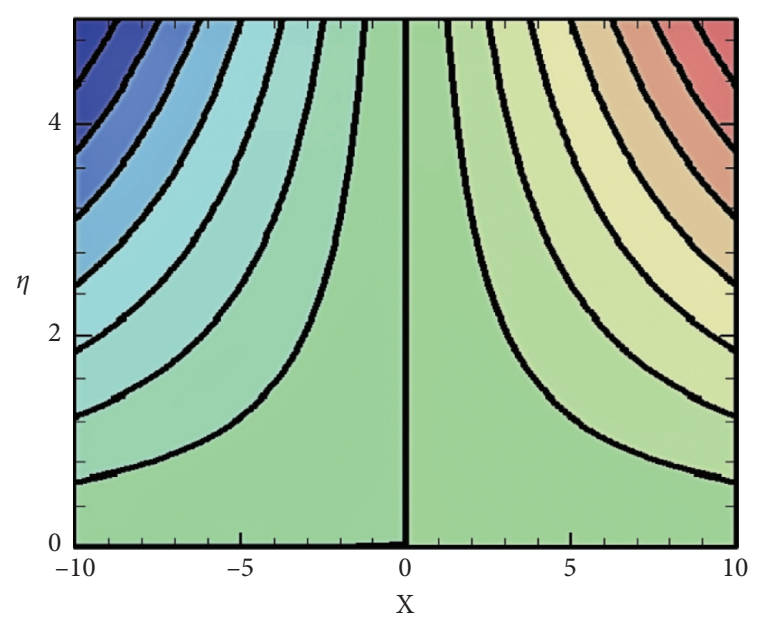

Figure 31: Streamlines for $Z=0.1$. 


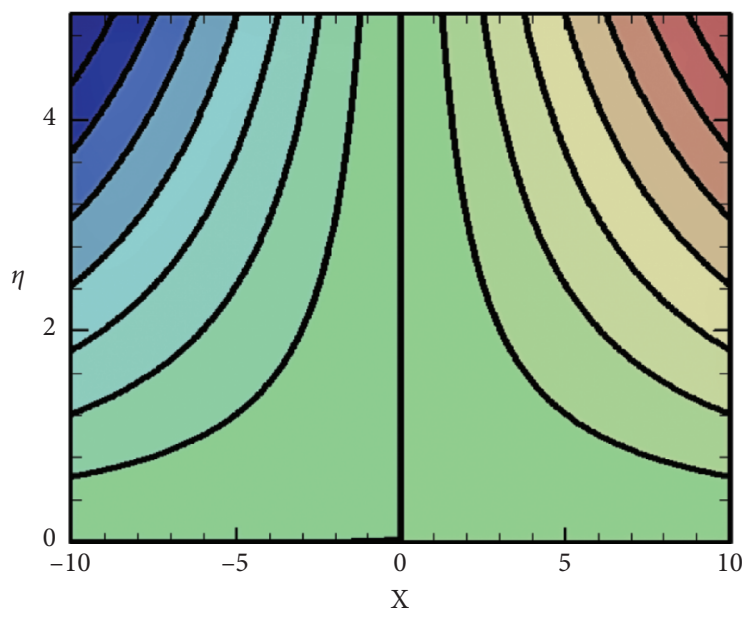

FIgURE 32: Streamlines for $Z=0.5$.

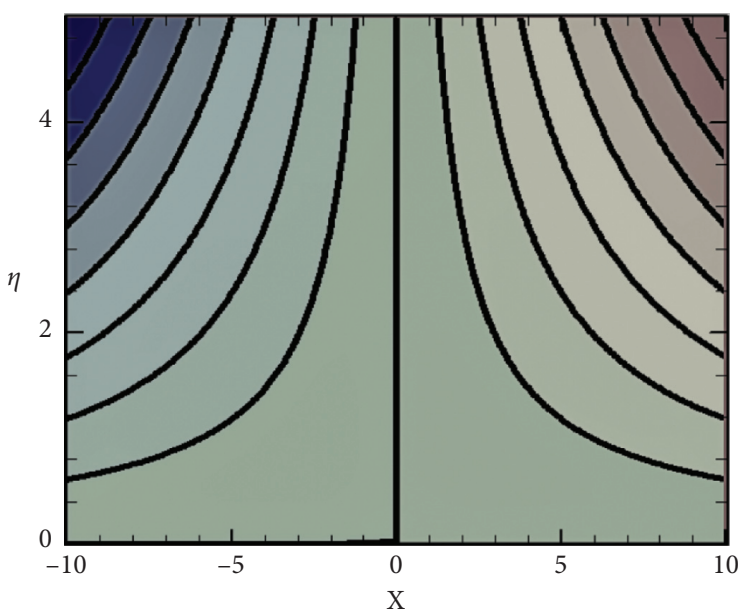

FIgURE 33: Streamlines for $Z=1$.

TABLE 1: Deviation of $N u_{x}\left(\operatorname{Re}_{x}\right)^{-(1 / 2)}$ for different amounts of characteristics.

\begin{tabular}{|c|c|c|c|c|c|c|c|c|c|c|c|c|c|c|}
\hline \multirow{2}{*}{$\lambda$} & \multirow{2}{*}{$\mathbf{N}_{\mathbf{r}}$} & \multirow{2}{*}{$\mathrm{Nb}$} & \multirow{2}{*}{$\mathrm{Nt}$} & \multirow{2}{*}{ Le } & \multirow{2}{*}{ d } & \multirow{2}{*}{$\mathbf{W}_{\mathrm{e}}$} & \multirow{2}{*}{$\mathbf{n}$} & \multirow{2}{*}{$\mathbf{B i}$} & \multirow{2}{*}{$\mathbf{Z}$} & \multirow{2}{*}{$\gamma$} & \multirow{2}{*}{ Pr } & \multicolumn{3}{|c|}{$\mathbf{N u}_{\mathbf{x}}\left(\mathbf{R e}_{\mathbf{x}}\right)^{-(1 / 2)}$} \\
\hline & & & & & & & & & & & & $r=0.5$ & $r=1$ & $r=2$ \\
\hline 0.1 & 0.1 & 0.1 & 0.1 & 0.1 & 1 & 0.1 & 1 & 0.1 & 0.1 & 0.1 & 7 & 0.09524 & 0.09550 & 0.09598 \\
\hline 0.5 & - & - & - & - & - & - & - & - & - & - & - & 0.09524 & 0.09550 & 0.09598 \\
\hline 1 & - & - & - & - & - & - & - & - & - & - & - & 0.09524 & 0.09550 & 0.09598 \\
\hline 0.1 & 0.1 & 0.1 & 0.1 & 0.1 & 1 & 0.1 & 1 & 0.1 & 0.1 & 0.1 & 7 & 0.09524 & 0.09550 & 0.09598 \\
\hline- & - & 1 & - & - & - & - & - & - & - & - & - & 0.09526 & 0.09551 & 0.09600 \\
\hline - & - & 2 & - & - & - & - & - & - & - & - & - & 0.09528 & 0.09553 & 0.09601 \\
\hline 0.1 & 1 & 0.1 & 0.1 & 0.1 & 1 & 0.1 & 1 & 2 & 0.5 & 1 & 7 & 1.02513 & 1.04844 & 1.10026 \\
\hline- & - & - & 1 & - & - & - & - & - & - & - & - & 1.04508 & 1.06400 & 1.10922 \\
\hline- & - & - & 3 & - & - & - & - & - & - & - & - & 1.07624 & 1.09004 & 1.12598 \\
\hline 0.1 & 1 & 0.1 & 0.1 & 0.1 & 1 & 0.1 & 1 & 0.1 & 0.5 & 1 & 7 & 0.09530 & 0.09554 & 0.09601 \\
\hline- & - & - & - & 0.3 & - & - & - & - & - & - & - & 0.09533 & 0.09556 & 0.09602 \\
\hline- & - & - & - & 0.5 & - & - & - & - & - & - & - & 0.09536 & 0.09558 & 0.09603 \\
\hline 0.1 & 1 & 0.1 & 0.1 & 0.1 & 1 & 0.1 & 1 & 0.1 & 0.5 & 1 & 7 & 0.09530 & 0.09554 & 0.09601 \\
\hline- & - & - & - & - & - & - & - & 0.5 & - & - & - & 0.40213 & 0.40619 & 0.41437 \\
\hline - & - & - & - & - & - & - & - & 1 & - & - & - & 0.67496 & 0.68576 & 0.70853 \\
\hline 0.1 & 1 & 0.1 & 0.1 & 0.1 & 1 & 0.1 & 1 & 0.1 & 0.5 & 1 & 7 & 0.09530 & 0.09554 & 0.09601 \\
\hline- & - & - & - & - & - & - & - & - & 1 & - & - & 0.09537 & 0.09559 & 0.09604 \\
\hline
\end{tabular}


TABLE 1: Continued.

\begin{tabular}{|c|c|c|c|c|c|c|c|c|c|c|c|c|c|c|}
\hline \multirow{2}{*}{$\lambda$} & \multirow{2}{*}{$\mathbf{N}_{\mathbf{r}}$} & \multirow{2}{*}{$\mathrm{Nb}$} & \multirow{2}{*}{$\mathrm{Nt}$} & \multirow{2}{*}{ Le } & \multirow{2}{*}{ d } & \multirow{2}{*}{$\mathbf{W}_{\mathrm{e}}$} & \multirow{2}{*}{$\mathbf{n}$} & \multirow{2}{*}{$\mathbf{B i}$} & \multirow{2}{*}{$\mathbf{Z}$} & \multirow[b]{2}{*}{$\gamma$} & \multirow{2}{*}{ Pr } & \multicolumn{3}{|c|}{$\mathbf{N u}_{\mathbf{x}}\left(\mathbf{R e}_{\mathbf{x}}\right)^{-(1 / 2)}$} \\
\hline & & & & & & & & & & & & $r=0.5$ & $r=1$ & $r=2$ \\
\hline- & - & - & - & - & - & - & - & - & 1.5 & - & - & 0.09544 & 0.09564 & 0.09606 \\
\hline 0.1 & 1 & 0.1 & 0.1 & 0.1 & 1 & 0.1 & 1 & 0.1 & 0.5 & 1 & 7 & 0.09530 & 0.09554 & 0.09601 \\
\hline- & - & - & - & - & - & - & - & - & - & 1.5 & - & 0.09528 & 0.09553 & 0.09601 \\
\hline- & - & - & - & - & - & - & - & - & - & 2 & - & 0.09527 & 0.09552 & 0.09600 \\
\hline 0.1 & 1 & 0.1 & 0.1 & 0.1 & 1 & 0.1 & 1 & 0.1 & 0.5 & 1 & 6.5 & 0.09513 & 0.09539 & 0.09588 \\
\hline- & - & - & - & - & - & - & - & - & - & - & 8.5 & 0.09573 & 0.09594 & 0.09634 \\
\hline- & - & - & - & - & - & - & - & - & - & - & 10.5 & 0.09616 & 0.09633 & 0.09667 \\
\hline
\end{tabular}

TABLE 2: Variation of $C_{f}\left(\operatorname{Re}_{x}\right)^{(1 / 2)}$ for different amounts of characteristics.

\begin{tabular}{|c|c|c|c|c|c|c|c|c|c|c|c|c|c|c|}
\hline \multirow{2}{*}{$\lambda$} & \multirow{2}{*}{$\mathbf{N}_{\mathbf{r}}$} & \multirow{2}{*}{$\mathrm{Nb}$} & \multirow{2}{*}{$\mathrm{Nt}$} & \multirow{2}{*}{ Le } & \multirow{2}{*}{ d } & \multirow{2}{*}{$\mathrm{w}_{\mathrm{e}}$} & \multirow{2}{*}{$\mathbf{n}$} & \multirow{2}{*}{$\mathrm{Bi}$} & \multirow{2}{*}{$\mathrm{Z}$} & \multirow{2}{*}{$\gamma$} & \multirow{2}{*}{ Pr } & \multicolumn{3}{|c|}{$C_{f}\left(\operatorname{Re}_{x}\right)^{(1 / 2)}$} \\
\hline & & & & & & & & & & & & $r=0.5$ & $r=1$ & $r=2$ \\
\hline 0.1 & 0.1 & 0.01 & 0.1 & 0 & 1 & 1 & 1 & 0.1 & 0.1 & 1.5 & 7 & -0.61859 & 0.04466 & 2.05609 \\
\hline 0.5 & - & - & - & - & - & - & - & - & - & - & - & -0.61406 & 0.04859 & 2.05910 \\
\hline 1 & - & - & - & - & - & - & - & - & - & - & - & -0.60839 & 0.05350 & 2.06286 \\
\hline 0.1 & 0.1 & 0.1 & 0.1 & 0.1 & 1 & 1 & 1 & 0.1 & 0.1 & 1.5 & 7 & -0.62883 & 0.03580 & 2.04931 \\
\hline- & - & 0.5 & - & - & - & - & - & - & - & - & - & -0.62427 & 0.03975 & 2.05233 \\
\hline- & - & 1 & - & - & - & - & - & - & - & - & - & -0.61859 & 0.04466 & 2.05609 \\
\hline 0.1 & 0.1 & 0.1 & 0.1 & 0.1 & 1 & 0.1 & 1 & 0.1 & 0.1 & 1.5 & 7 & -0.62546 & 0.03869 & 2.05167 \\
\hline- & - & - & 1 & - & - & - & - & - & 1 & - & - & -0.30441 & 0.34063 & 2.32326 \\
\hline- & - & - & 3 & - & - & - & - & - & 1.5 & - & - & -0.12896 & 0.50656 & 2.47328 \\
\hline 0.1 & 0.1 & 0.1 & 0.1 & 0.1 & 1 & 0.1 & 1 & 0.1 & 0.1 & 0.1 & 7 & -0.57767 & 0.07476 & 2.07641 \\
\hline- & - & - & - & - & - & - & - & - & - & 1 & - & -0.61658 & 0.04606 & 2.05726 \\
\hline- & - & - & - & - & - & - & - & - & - & 2 & - & -0.63130 & 0.03363 & 2.04763 \\
\hline
\end{tabular}

numerically become constant. Table 2 shows numerical values of the skin friction coefficient. By increased values of $\lambda, N_{r}$, and $Z$, friction coefficient gets larger and friction reduced by higher values of $\gamma$.

\section{Conclusion}

The following main resulting ideas are taken into account:

(i) Fluctuations of velocity were examined for some physical parameters; profile increases when $Z, \lambda$, $N_{r}, B i, N t$, and $r$ increase; on the other hand, it declines if $W_{e}$, $\operatorname{Pr}, \gamma$, and $N b$ get larger.

(ii) It can be revealed that thermal boundary layer width gets down when the values of Le, $r, N t, \operatorname{Pr}$, and $Z$ incline, and it becomes larger for higher values of $B i, \gamma$, and $N b$.

(iii) It can be easily observed that concentration patterns increase when the values of $Z, N b$, Pr, and $r$ move upward and concentration boundary layer width diminishes, whereas it inclines in $\gamma, \mathrm{Nt}, \mathrm{Bi}$, and $L e$.

(iv) When the values of the parameters $N b, N t, L e$, $B i, \operatorname{Pr}$, and $Z$ incline, that caused heat transfer coefficient upgrade and degrade by the increase of $\gamma$. The consequences of $\lambda$ on Nusselt numbers numerically become constant. (v) The numerical values of the skin friction coefficient increase by increasing the values of $\lambda, N_{r}$, and $Z$. The friction coefficient gets reduced by higher values of $\gamma$.

\section{Abbreviations}

$C_{f}: \quad$ Skin friction coefficient (-)

b: $\quad$ Body forces $\left(\mathrm{Nm}^{-3}\right)$

$C_{\infty}: \quad$ Ambient fluid concentration $\left(\mathrm{kgm}^{-3}\right)$

$\varphi: \quad$ Dimensionless concentration function (-)

$\mathrm{Bi}$ : Biot number

$D_{T}$ : Thermophoresis diffusion coefficient $\left(\mathrm{m}^{2} \mathrm{~s}^{-1}\right)$

$C: \quad$ Nanoparticles concentration $\left(\mathrm{kgm}^{-3}\right)$

$D_{B}$ : Brownian diffusion coefficient $\left(\mathrm{m}^{2} \mathrm{~s}^{-1}\right)$

$f: \quad$ Dimensionless velocity function $(-)$

$g: \quad$ Gravity acceleration $\left(\mathrm{ms}^{-2}\right)$

$h_{f}$ : Convection coefficient

$S h_{x}$ : Local Sherwood number (-)

$N u_{x}$ : Local Nusselt number (-)

$\mathrm{Re}_{x}$ : Local Reynolds number (-)

Nt: Thermophoresis parameter (-)

$T_{\infty}$ : Ambient temperature $(K)$

$\mathrm{Nb}$ : Brownian motion parameter (-)

$\eta$ : $\quad$ Similarity variable $(-)$

$K: \quad$ Thermal conductivity

$u_{w}$ : Stretching sheet velocity $\left(\mathrm{ms}^{-1}\right)$

$T_{f}$ : Hot fluid temperature $(K)$ 
$u_{\infty}: \quad$ External flow velocity $\left(\mathrm{ms}^{-1}\right)$

$(u, v)$ : Velocity components $\left(\mathrm{ms}^{-1}\right)$

$(x, y)$ : Cartesian coordinate components $(m)$

$W_{e}: \quad$ Weissenberg number

$\Gamma: \quad$ Time fluid parameter

$\tau: \quad$ Extra stress tensor (-)

$n$ : $\quad$ Power index

$d: \quad$ Fluid characteristics (-)

$N_{r}$ : Buoyancy ratio parameter (-)

$a_{1}$ : Width of the magnet between electrodes

$\mu_{0}: \quad$ Zero shear rate viscosity

$\lambda$ : $\quad$ Mixed convection parameter

$\tau_{w}: \quad$ Surface shear stress (-)

$\rho_{p}: \quad$ The density of the nanoparticles $\left(\mathrm{kgm}^{-3}\right)$

$q_{m}: \quad$ Surface mass flux (-)

$\rho_{f}: \quad$ The density of the base fluid $\left(\mathrm{kgm}^{-3}\right)$

$j_{0}$ : Applied current density

$\rho: \quad$ Density $\left(\mathrm{kgm}^{-3}\right)$

Pr: $\quad$ Prandtl number (-)

$q_{w}: \quad$ Surface heat flux $(-)$

$\gamma$ : Width parameter

$n p: \quad$ Nanoparticle (-)

$r$ : $\quad$ Stretching parameter (-)

$\mu_{\infty}: \quad$ Infinite shear rate viscosity

$M_{0}$ : Magnetization of permanent magnets

$A_{1}$ : Rivlin-Ericksen tensor (-)

T: $\quad$ Temperature (-)

$\theta$ : The dimensionless heat temperature function (-)

$\alpha: \quad$ Thermal diffusivity $\left(\mathrm{m}^{2} \mathrm{~s}^{-1}\right)$

$Z$ : $\quad$ Modified Hartmann number

Le: $\quad$ Lewis number $(-)$.

\section{Data Availability}

The data used to support the findings of the study are available from the corresponding author upon request.

\section{Conflicts of Interest}

The authors declare that they have no conflicts of interest.

\section{References}

[1] A. Jamaludin, R. Nazar, and I. Pop, "Mixed convection stagnation-point flow of a nanofluid past a permeable stretching/shrinking sheet in the presence of thermal radiation and heat source/sink," Energies, vol. 12, no. 5, p. 788, 2019.

[2] Y. S. Daniel, Z. A. Aziz, Z. Ismail, A. Bahar, and F. Salah, "Slip role for unsteady MHD mixed convection of nanofluid over stretching sheet with thermal radiation and electric field," Indian Journal of Physics, vol. 94, pp. 195-207, 2020.

[3] H. R. Patel and R. Singh, "Thermophoresis, Brownian motion and non-linear thermal radiation effects on mixed convection MHD micropolar fluid flow due to nonlinear stretched sheet in porous medium with viscous dissipation, joule heating and convective boundary condition," International Communications in Heat and Mass Transfer, vol. 107, pp. 68-92, 2019.

[4] N. S. Arifin, S. M. Zokri, A. R. M. Kasim, M. Z. Salleh, and N. F. Mohammad, "Two-phase mixed convection flow of dusty Williamson fluid with aligned magnetic field over a vertical stretching sheet," in Proceedings of the Third International Conference on Computing, Mathematics and Statistics (iCMS2017), pp. 209-216, Langkawi, Malaysia, January 2019.

[5] A. Ishak, R. Nazar, and I. Pop, "Mixed convection boundary layers in the stagnation-point flow toward a stretching vertical sheet," Meccanica, vol. 41, no. 5, pp. 509-518, 2006.

[6] A. Shafiq, G. Rasool, C. M. Khalique, and S. Aslam, "Second grade bioconvective nanofluid flow with buoyancy effect and chemical reaction," Symmetry, vol. 12, no. 4, p. 621, 2020.

[7] K. Naganthran, R. Nazar, and I. Pop, "A study on nonNewtonian transport phenomena in a mixed convection stagnation point flow with numerical simulation and stability analysis," The European Physical Journal Plus, vol. 134, no. 3, p. 105, 2019.

[8] S. N. A. Azeman and A. M. Ishak, "Mixed convection flow near a stagnation point on a vertical surface with prescribed surface heat flux," Journal of Physics: Conference Series, vol. 1212, no. 1, p. 012029, 2019.

[9] F. M. Ali, K. Naganthran, R. Nazar, and I. Pop, "MHD mixed convection boundary layer stagnation-point flow on a vertical surface with induced magnetic field," International Journal of Numerical Methods for Heat \& Fluid Flow, vol. 30, no. 11, 2019.

[10] G. Rasool and A. Wakif, "Numerical spectral examination of EMHD mixed convective flow of second-grade nanofluid towards a vertical Riga plate using an advanced version of the revised Buongiorno's nanofluid model," Journal of Thermal Analysis and Calorimetry, vol. 143, no. 3, pp. 2379-2393, 2021.

[11] B. Golafshan and A. B. Rahimi, "Effects of radiation on mixed convection stagnation-point flow of MHD third-grade nanofluid over a vertical stretching sheet," Journal of Thermal Analysis and Calorimetry, vol. 135, no. 1, pp. 533-549, 2019.

[12] H. A. Ogunseye, P. Sibanda, and H. Mondal, "MHD mixed convective stagnation-point flow of Eyring-Powell nanofluid over stretching cylinder with thermal slip conditions," Journal of Central South University, vol. 26, no. 5, pp. 1172-1183, 2019.

[13] N. F. M. Noor, R. U. Haq, S. Nadeem, and I. Hashim, "Mixed convection stagnation flow of a micropolar nanofluid along a vertically stretching surface with slip effects," Meccanica, vol. 50, no. 8, pp. 2007-2022, 2015.

[14] T. Hayat and S. Nadeem, "The effects of MHD and buoyancy on Hematite water-based fluid past a convectively heated stretching sheet," Neural Computing and Applications, vol. 31, no. 4, pp. 1083-1090, 2019.

[15] S. Ahmad, S. Nadeem, and N. Muhammad, "Boundary layer flow over a curved surface imbedded in porous medium," Communications in Theoretical Physics, vol. 71, no. 3, p. 344, 2019.

[16] A. F. Al-Hossainy and M. R. Eid, "Structure, DFT calculations and heat transfer enhancement in $[\mathrm{ZnO} / \mathrm{PG}+\mathrm{H} 2 \mathrm{O}] \mathrm{C}$ hybrid nanofluid flow as a potential solar cell coolant application in a double-tube," Journal of Materials Science: Materials in Electronics, vol. 31, no. 5-6, pp. 15243-15257, 2020.

[17] A. Zaib, R. U. Haq, A. J. Chamkha, and M. M. Rashidi, "Impact of partial slip on mixed convective flow towards a Riga plate comprising micropolar TiO2-kerosene/water nanoparticles," International Journal of Numerical Methods for Heat \& Fluid Flow, vol. 29, no. 8, 2019.

[18] S. U. Choi and J. A. Eastman, "Enhancing thermal conductivity of fluids with nanoparticles," in Proceedings of the 1995 International Mechanical Engineering Congress and Exhibition, San Francisco, CA, USA, November 1995. 
[19] Z. Ahmed, S. Nadeem, S. Saleem, and R. Ellahi, "Numerical study of unsteady flow and heat transfer CNT-based MHD nanofluid with variable viscosity over a permeable shrinking surface," International Journal of Numerical Methods for Heat \& Fluid Flow, vol. 29, no. 12, 2019.

[20] S. Saleem, H. Firdous, S. Nadeem, and A. U. Khan, "Convective heat and mass transfer in magneto Walter's B nanofluid flow induced by a rotating cone," Arabian Journal for Science and Engineering, vol. 44, no. 2, pp. 1515-1523, 2019.

[21] G. Rasool, A. Shafiq, and C. M. Khalique, "Marangoni forced convective Casson type nanofluid flow in the presence of Lorentz force generated by Riga plate," Discrete \& Continuous Dynamical Systems - S, 2021.

[22] A. Hussain, L. Sarwar, S. Akbar, M. Y. Malik, and S. Ghafoor, "Model for MHD viscoelastic nanofluid flow with prominence effects of radiation," Heat Transfer-Asian Research, vol. 48, no. 2, pp. 463-482, 2019.

[23] A. A. Alaidrous and M. R. Eid, "3-D electromagnetic radiative non-Newtonian nanofluid flow with Joule heating and higherorder reactions in porous materials," Scientific Reports, vol. 10, no. 1, pp. 1-19, 2020.

[24] A. Hussain, L. Sarwar, S. Akbar, S. Nadeem, and S. Jamal, "Numerical investigation of viscoelastic nanofluid flow with radiation effects," Proceedings of the Institution of Mechanical Engineers, Part N: Journal of Nanomaterials, Nanoengineering and Nanosystems, vol. 233, no. 2-4, 2019.

[25] A. Hussain, A. Rehman, S. Nadeem et al., "A combined convection carreau-yasuda nanofluid model over a convective heated surface near a stagnation point: a numerical study," Mathematical Problems in Engineering, vol. 2021, Article ID 6665743, 14 pages, 2021.

[26] F. Hussain, A. Hussain, and S. Nadeem, "Thermophoresis and Brownian model of pseudo-plastic nanofluid flow over a vertical slender cylinder," Mathematical Problems in Engineering, vol. 2020, Article ID 8428762, , 2020.

[27] G. Rasool, W. A. Khan, S. M. Bilal, and I. Khan, "MHD squeezed Darcy-Forchheimer nanofluid flow between two h-distance apart horizontal plates," Open Physics, vol. 18, no. 1, pp. 1100-1107, 2020.

[28] R. Fares, F. Mebarek-Oudina, A. Aissa, S. M. Bilal, and H. F. Öztop, "Optimal entropy generation in Darcy-Forchheimer magnetized flow in a square enclosure filled with silver based water nanoliquid," Journal of Thermal Analysis and Calorimetry, pp. 1-11, 2021.

[29] S. Nadeem, M. N. Khan, M. N. Khan, N. Muhammad, and S. Ahmad, "Erratum to: mathematical analysis of bio-convective micropolar nanofluid erratum to: Journal of computational Design and engineering," Journal of Computational Design and Engineering, vol. 6, no. 3, 2019.

[30] A. Hussain, S. Akbar, L. Sarwar, and S. Nadeem, "Probe of radiant flow on temperature-dependent viscosity models of differential type MHD fluid," Mathematical Problems in Engineering, vol. 2020, Article ID 2927013, , 2020.

[31] H. Alotaibi, S. Althubiti, M. R. Eid, and K. L. Mahny, "Numerical treatment of mhd flow of casson nanofluid via convectively heated non-linear extending surface with viscous dissipation and suction/injection effects," Computers, Materials \& Continua, vol. 66, no. 1, pp. 229-245, 2021.

[32] F. Mebarek-Oudina, A. K. Hussein, O. Younis, S. Rostami, and R. Nikbakhti, "Natural convection enhancement in the annuli between two homocentric cylinders by using ethylene glycol/water based titania nanofluid," Journal of Advanced
Research in Fluid Mechanics and Thermal Sciences, vol. 80, no. 2, pp. 56-73, 2021.

[33] M. Subhani and S. Nadeem, "Numerical analysis of micropolar hybrid nanofluid," Applied Nanoscience, vol. 9, no. 4, pp. 447-459, 2019.

[34] K. Swain, F. Mebarek-Oudina, and S. M. Abo-Dahab, "Influence of MWCNT/ $/ \mathrm{Fe}_{3} \mathrm{O}_{4}$ hybrid nanoparticles on an exponentially porous shrinking sheet with chemical reaction and slip boundary conditions," Journal of Thermal Analysis and Calorimetry, pp. 1-10, 2021.

[35] G. Rasool and A. Shafiq, "Numerical exploration of the features of thermally enhanced chemically reactive radiative Powell-Eyring nanofluid flow via Darcy medium over nonlinearly stretching surface affected by a transverse magnetic field and convective boundary conditions," Applied Nanoscience, pp. 1-18, 2020.

[36] S. Waheed, A. Saleem, and S. Nadeem, "Physiological analysis of streamline topologies and their bifurcations for a peristaltic flow of nano fluid," Microsystem Technologies, vol. 25, no. 4, pp. 1267-1296, 2019.

[37] A. Rehman, A. Hussain, and S. Nadeem, "Physical aspects of convective and radiative molecular theory of liquid originated nanofluid flow in the existence of variable properties," Physica Scripta, vol. 96, no. 3, p. 035219, 2021.

[38] M. R. Eid, “Thermal characteristics of 3D nanofluid flow over a convectively heated Riga surface in a Darcy-forchheimer porous material with linear thermal radiation: an optimal analysis," Arabian Journal for Science and Engineering, vol. 45, no. 11, pp. 9803-9814, 2020.

[39] M. Subhani and S. Nadeem, "Numerical investigation of unsteady MHD flow of micropolar hybrid nanofluid in porous medium," Physica Scripta, vol. 94, no. 10, 2019.

[40] T. W. Berger, J. Kim, C. Lee, and J. Lim, “Turbulent boundary layer control utilizing the Lorentz force," Physics of Fluids, vol. 12, no. 3, pp. 631-649, 2000.

[41] J. Pang and K.-S. Choi, "Turbulent drag reduction by Lorentz force oscillation," Physics of Fluids, vol. 16, no. 5, pp. L35-L38, 2004.

[42] S. Nadeem, M. Y. Malik, and N. Abbas, "Heat transfer of three dimensional micropolar fluids on Riga plate," Canadian Journal of Physics, vol. 98, no. 1, 2020.

[43] A. Mahdy and G. Hoshoudy, "EMHD time-dependant tangent hyperbolic nanofluid flow by a convective heated Riga plate with chemical reaction," Proceedings of the Institution of Mechanical Engineers, Part E: Journal of Process Mechanical Engineering, vol. 233, no. 4, pp. 776-786, 2019.

[44] M. Khan, A. Shahid, M. Y. Malik, and T. Salahuddin, "Chemical reaction for Carreau-Yasuda nanofluid flow past a nonlinear stretching sheet considering Joule heating," Results in Physics, vol. 8, pp. 1124-1130, 2018. 